\title{
An Atlas of ShakeMaps for Selected Global Earthquakes
}

\author{
USGS ShakeMap : Niigata, Japan
}

Sat Oct 23, 2004 08:56:00 GMT M 6.6 N37.23 E138.80 Depth: 16.0km ID:200410230856

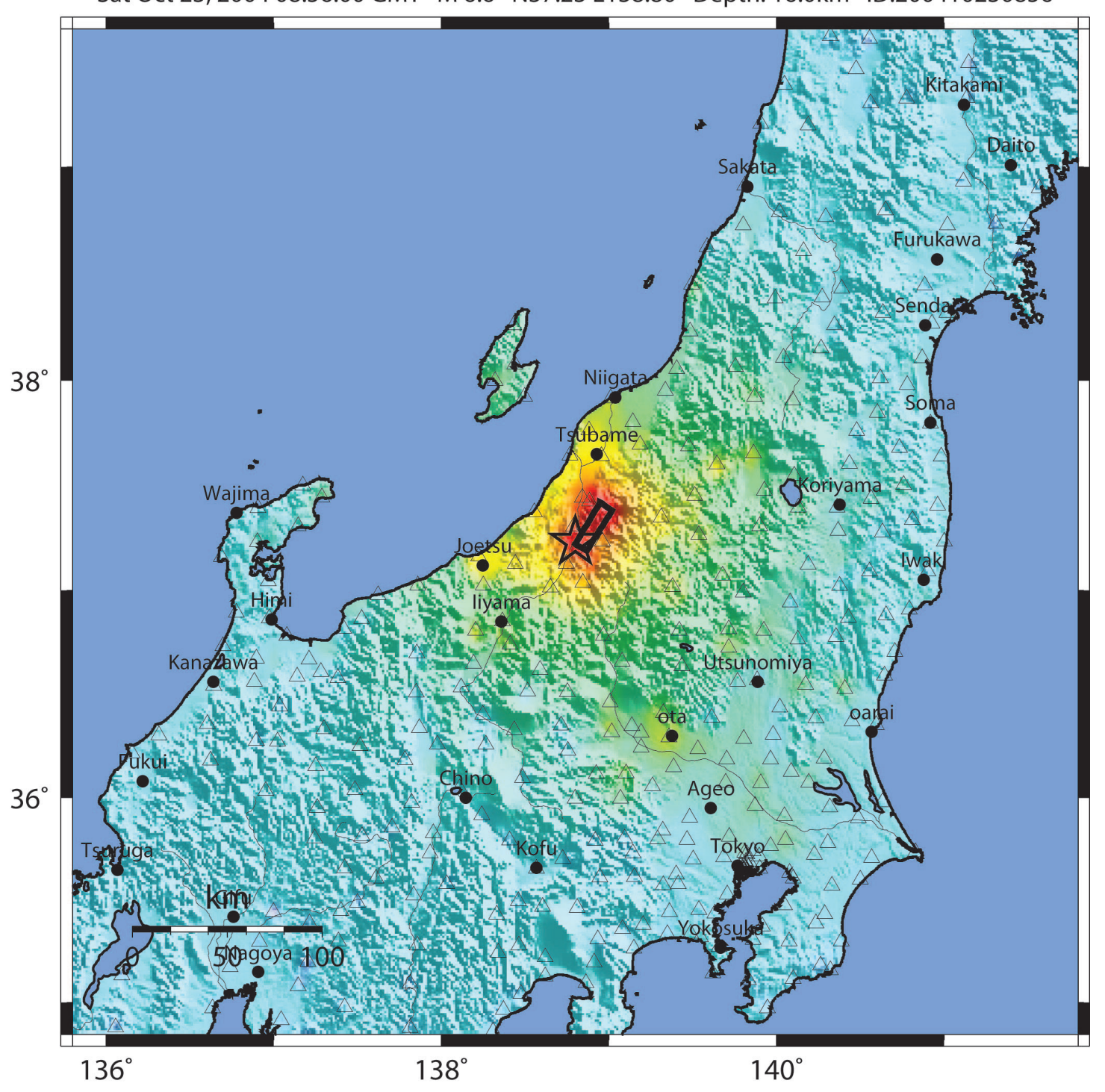

Open-File Report 2008-1236 


\section{An Atlas of ShakeMaps for Selected Global Earthquakes}

By Trevor I. Allen, David J. Wald, Alicia J. Hotovec, Kuowan Lin, Paul S. Earle, and Kristin D. Marano

Open-File Report 2008-1236

U.S. Department of the Interior

U.S. Geological Survey 


\section{U.S. Department of the Interior DIRK KEMPTHORNE, Secretary}

\section{U.S. Geological Survey \\ Mark D. Myers, Director}

U.S. Geological Survey, Reston, Virginia: 2008

For product and ordering information:

World Wide Web: http://www.usgs.gov/pubprod

Telephone: 1-888-ASK-USGS

For more information on the USGS - the Federal source for science about the Earth, its natural and living resources, natural hazards, and the environment:

World Wide Web: http://www.usgs.gov

Telephone: 1-888-ASK-USGS

Any use of trade, product, or firm names is for descriptive purposes only and does not imply endorsement by the U.S. Government.

Although this report is in the public domain, permission must be secured from the individual copyright owners to reproduce any copyrighted materials contained within this report.

Suggested citation:

Allen, T.I., Wald, D.J., Hotovec, A.J., Lin, K., Earle, P.S. and Marano, K.D., 2008, An Atlas of ShakeMaps for Selected Global Earthquakes: U.S. Geological Survey Open-File Report 2008-1236, 35 p. 


\section{Contents}

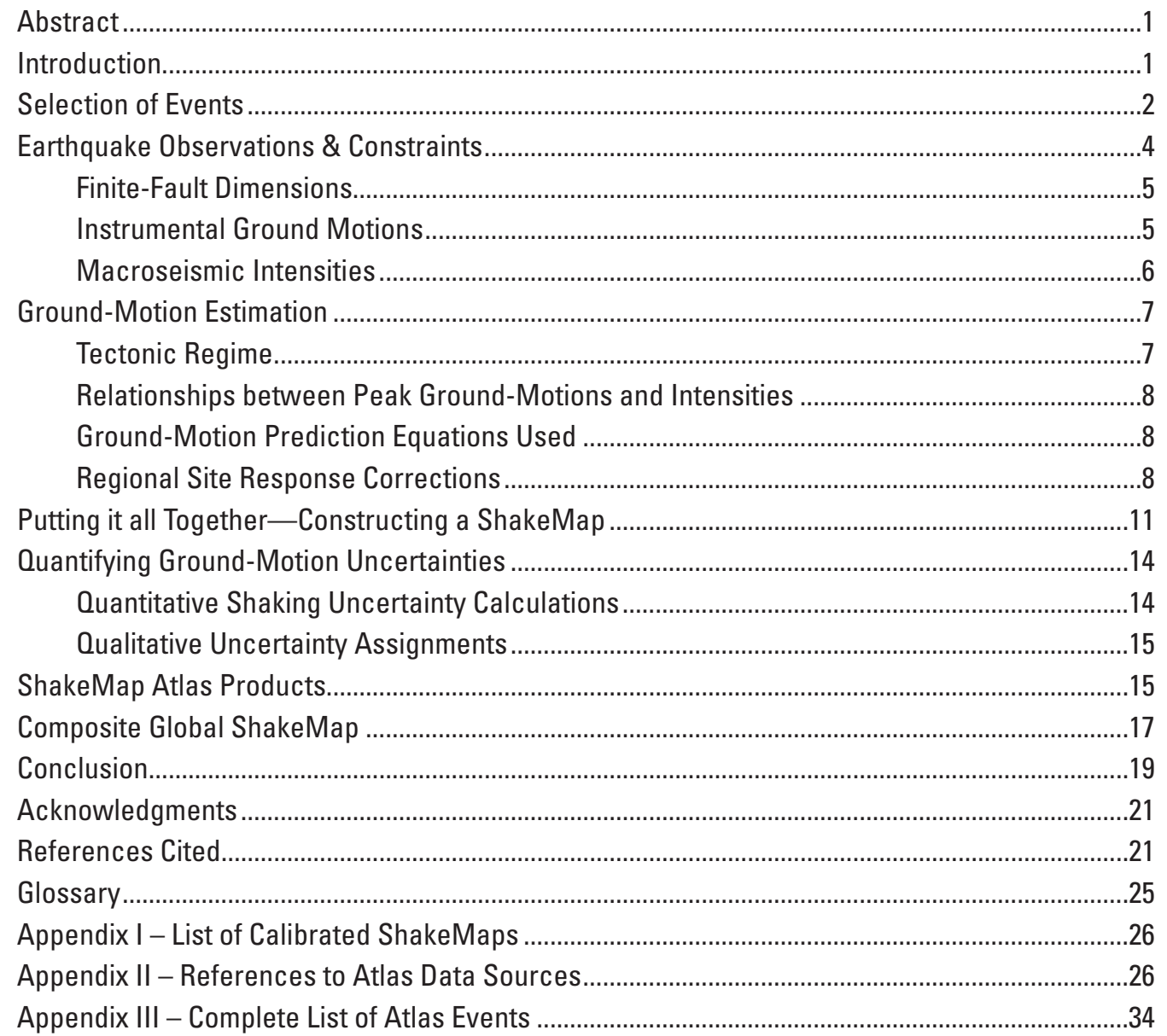




\section{Figures}

1. Some examples of ShakeMaps contained within the Atlas.................................................

2. Logic tree defining default tectonic environment............................................................

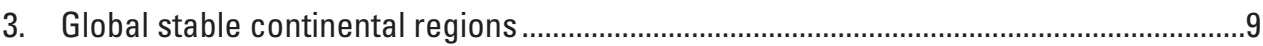

4. A, Topographic map of the San Francisco Bay Area. B, Seismic site-condition map based on geology and $V_{s}^{30}$ observations (modified from Wills and others, 2000). C, Site-condition map derived from topographic slope. $D$, The ratio of the predicted amplification for a uniform PGA of $250 \mathrm{~cm} / \mathrm{s}^{2}$ for the geologically- and topographically-based $V_{s}^{30}$ maps.................................................10

5. Evolution of the Pisco, Peru earthquake 15th August $2007 M_{w} 8.0$ ShakeMap................12

6. Evolution of the Umbria-Marche, Italy earthquake 26th September 1997 $M_{w} 6.0$ ShakeMap...

7. Evolution of the Kythira Island, Greece earthquake 6th January 2006 the $M_{w} 6.7$ ShakeMap

8. Examples of ShakeMap uncertainty grids. 16

9. A Combined Atlas ShakeMaps indicating the maximum PGA estimated at any location in the World, and $B$ the Global Seismic Hazard Map (GSHAP)

10. A Combined PGA for Atlas ShakeMaps for South America, and $B$ the percentage exceedance of the estimated PGA from 1973 to September 2007 relative to the GSHAP hazard map

\section{Tables}

1. Summary of instrumental data constraining earthquakes in the Atlas of ShakeMaps....6

2. Summary of macroseismic intensity and DYFI? data constraining earthquakes in the Atlas of ShakeMaps.

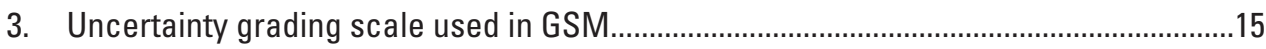

4. Percentage of landmass exceeding the GSHAP hazard map for different regions in the world from January 1973 to September 2007 


\title{
An On-line Atlas of ShakeMaps for Selected Global Earthquakes
}

\author{
By T.I. Allen, ${ }^{1}$ D.J. Wald, ${ }^{2}$ A.J. Hotovec ${ }^{2}$ K.Lin, ${ }^{2}$ P.S. Earle, ${ }^{2}$ and K.D. Marano ${ }^{2}$
}

\section{Abstract}

An atlas of maps of peak ground motions and intensity "ShakeMaps" has been developed for almost 5,000 recent and historical global earthquakes. These maps are produced using established ShakeMap methodology (Wald and others, $1999 \mathrm{c}$; Wald and others, 2005) and constraints from macroseismic intensity data, instrumental ground motions, regional topographically-based site amplifications, and published earthquake-rupture models. Applying the ShakeMap methodology allows a consistent approach to combine point observations with ground-motion predictions to produce descriptions of peak ground motions and intensity for each event. We also calculate an estimated ground-motion uncertainty grid for each earthquake.

The Atlas of ShakeMaps provides a consistent and quantitative description of the distribution and intensity of shaking for recent global earthquakes (1973-2007) as well as selected historic events. As such, the Atlas was developed specifically for calibrating global earthquake loss estimation methodologies to be used in the U.S. Geological Survey Prompt Assessment of Global Earthquakes for Response (PAGER) Project. PAGER will employ these loss models to rapidly estimate the impact of global earthquakes as part of the USGS National Earthquake Information Center's earthquake-response protocol.

The development of the Atlas of ShakeMaps has also led to several key improvements to the Global ShakeMap system. The key upgrades include: addition of uncertainties in the ground motion mapping, introduction of modern groundmotion prediction equations, improved estimates of global seismic-site conditions $\left(\mathrm{V}_{\mathrm{s}}{ }^{30}\right)$, and improved definition of stable continental region polygons. Finally, we have merged all of the ShakeMaps in the Atlas to provide a global perspective of earthquake ground shaking for the past 35 years, allowing comparison with probabilistic hazard maps. The online Atlas and supporting databases can be found at http://earthquake. usgs.gov/eqcenter/shakemap/atlas.php/.

${ }^{1}$ U.S. Geological Survey Geologic Hazards Team, 1711 Illinois St., Golden, CO 80401 (contracted through Synergetics Incorporated)

${ }^{2}$ U.S. Geological Survey Geologic Hazards Team, 1711 Illinois St., Golden, CO 80401

\section{Introduction}

ShakeMap was first developed to provide near realtime maps of ground motion and shaking intensity following significant earthquakes in California (1999c). The system is designed to combine instrumental measurements with information about local seismic site conditions and the earthquake source to estimate continuous shaking variations throughout a spatial area (Wald and others, 2005). The benefit and application to other regions was soon recognized and ShakeMap was implemented in other high-to-moderate-risk areas where rapid assessment of earthquakes is critical (for example, Utah, Alaska, Washington and Oregon, Nevada, Puerto Rico, Italy, and other areas). The U.S. Geological Survey's (USGS) ShakeMap program was subsequently extended in 2004 with the addition of Global ShakeMap, which uses the USGS National Earthquake Information Center's (NEIC) hypocenters and other available constraints to generate ShakeMaps for earthquakes occurring anywhere in the world in near real-time.

While the rapid definition of the distribution and intensity of shaking is critically important, some immediate measure of the actual impact of an earthquake in terms of lives and property in peril is critically needed for response. The Prompt Assessment of Global Earthquakes for Response (PAGER, Wald and others, 2006a) provides a natural progression from rapid ShakeMap hazard evaluation into the post-earthquake response and loss arena. PAGER shaking input is built on the Global ShakeMap methodologies to provide near real-time assessments of an earthquake's impact. The Global ShakeMaps produced for PAGER are fundamentally predictive rather than data-driven, relying heavily on calculated source parameters (that is, hypocenter and magnitude), groundmotion prediction equations, and first-order assessments of regional site amplification (Wald and Allen, 2007). This is in contrast to fundamentally data-constrained ShakeMaps currently produced in places like California, where real-time ground-motion recordings are abundant. Additional constraints provided by the USGS's community internet intensityreporting system "Did You Feel It?" (Wald and others, 1999a), as well as from rapid teleseismic estimates of fault rupture dimensions and near-source ground-motion recordings will 
further refine Global ShakeMap shaking estimates within hours of an event, when and where they become available.

The primary motivation for developing the online Atlas of ShakeMaps is to support the development of PAGER lossestimation methodologies. The Atlas will provide a global, uniformly-derived set of ShakeMaps for numerous recenthistoric earthquakes (since 1973). Calibration of loss methodologies for PAGER relies on accurately estimating exposures (both human and the built environment) at each observed shaking intensity level. Exposure estimates from Atlas events are currently being correlated with documented earthquake casualty and damage information to derive loss models, and this is the subject of ongoing research (Jaiswal and others, 2008; Porter and others, 2008). Though developed primarily for PAGER, we anticipate many other uses for the historical ShakeMap Atlas, including disaster response planning, and capacity building and outreach programs, in addition to calibration of other global loss methodology approaches. Figure 1 presents an example of some of the historical earthquakes included in the Atlas of ShakeMaps.

Since the science, data availability, and further earthquake studies continue to improve our capacity to estimate shaking for earthquakes in the Atlas, we expect to update many or all events in the Atlas on an occasional basis as these advancements become available. As such, we have developed a process of version-control to time stamp and label events for tracking purposes. ShakeMaps computed in the first release of the Atlas are labeled as version 1.0. In the sections that follow we describe the data collection and the ShakeMap system upgrades necessary for development of the online Atlas.

\section{Selection of Events}

The full Atlas earthquake-calibration list currently comprises almost 5,000 events from 1973 to September 2007. However, the online version of the Atlas is comprised only of those events that have some auxiliary information (about 450 at the time of writing) - that is, additional constraints that reduce the uncertainty of the shaking pattern. Initially, earthquakes were chosen because they resulted in large numbers of fatalities, or incurred large financial losses and damage to critical infrastructure. Consequently, these events were generally well-documented in the scientific literature. However, it was felt that this approach would heavily bias the Atlas (and potentially loss models) to events with high losses. Consequently, we chose to include numerous events that resulted in significant human populations being exposed to moderate-to-strong ground shaking, independent of whether they resulted in fatalities or other losses. This process involved several key steps outlined below.

We used the USGS's Preliminary Determination of Epicenters (PDE) as our primary event list (Sipkin and others, 2000). The full PDE catalogue comprises entries for almost 540,000 earthquakes of all magnitudes from January 1973 to the present (September 2007 at the time of analysis). Since we were only interested in earthquakes that were likely to have resulted in damage and fatalities, or were strongly felt by large population exposures, we had to impose criteria to objectively reduce the catalogue to a convenient number of events for ShakeMap calculations. To do this, we employed the following steps:

1. Only include earthquakes with a PDE preferred magnitude of $M 5.5$ and greater in active tectonic regions and $M 4.8$ in stable continental regions as defined by Johnston and others (Johnston and others, 1994)., Events that resulted in casualties that were not mining triggered or caused by other non-tectonic phenomena (for example, nuclear explosions) were also included. This reduces the dataset to approximately 15,000 earthquakes.

2. Associate well-located earthquake hypocenters from the updated Engdahl, van der Hilst and Buland (EHB) earthquake catalog (Engdahl and others, 1998) and centroid moment tensor magnitudes (Dziewonski and others, 1981) to events in the abridged PDE catalog. This was done so that consistently derived technical information could be used to calibrate the ShakeMaps (see PAGER-CAT at http://earthquake.usgs.gov/research/data/pager/).

3. Roughly approximate the total population exposed to at least "strong" shaking of Modified Mercalli Intensity (MMI) VI and above by:

3.1. Using the stable-continent ground-motion intensity relations outlined in Atkinson and Wald (2007), calculate the radius $R_{F}$ that observers would expect to have felt MMI VI and greater from the earthquake epicenter (that is, a point source). We chose the stable continent coefficients since they serve as a conservative estimate of the attenuation of shaking intensity with distance. This would result in a net over-estimation of the population exposed.

3.2 Estimate the fault rupture length L, from the preferred magnitude of the earthquake using the relations of Wells and Coppersmith (1994). The total search radius from the earthquake epicenter RS is therefore $\mathrm{RS}=\mathrm{RF}+\mathrm{L}$.

3.3 Aggregate the total population exposure within search radius $\mathrm{RS}$ of the epicenter using the LandScan 2005 global population database (for example, Dobson and others, 2000; Bhaduri and others, 2002). Note: in this step, we did not attempt to hindcast population exposure to the date of the particular earthquake. 

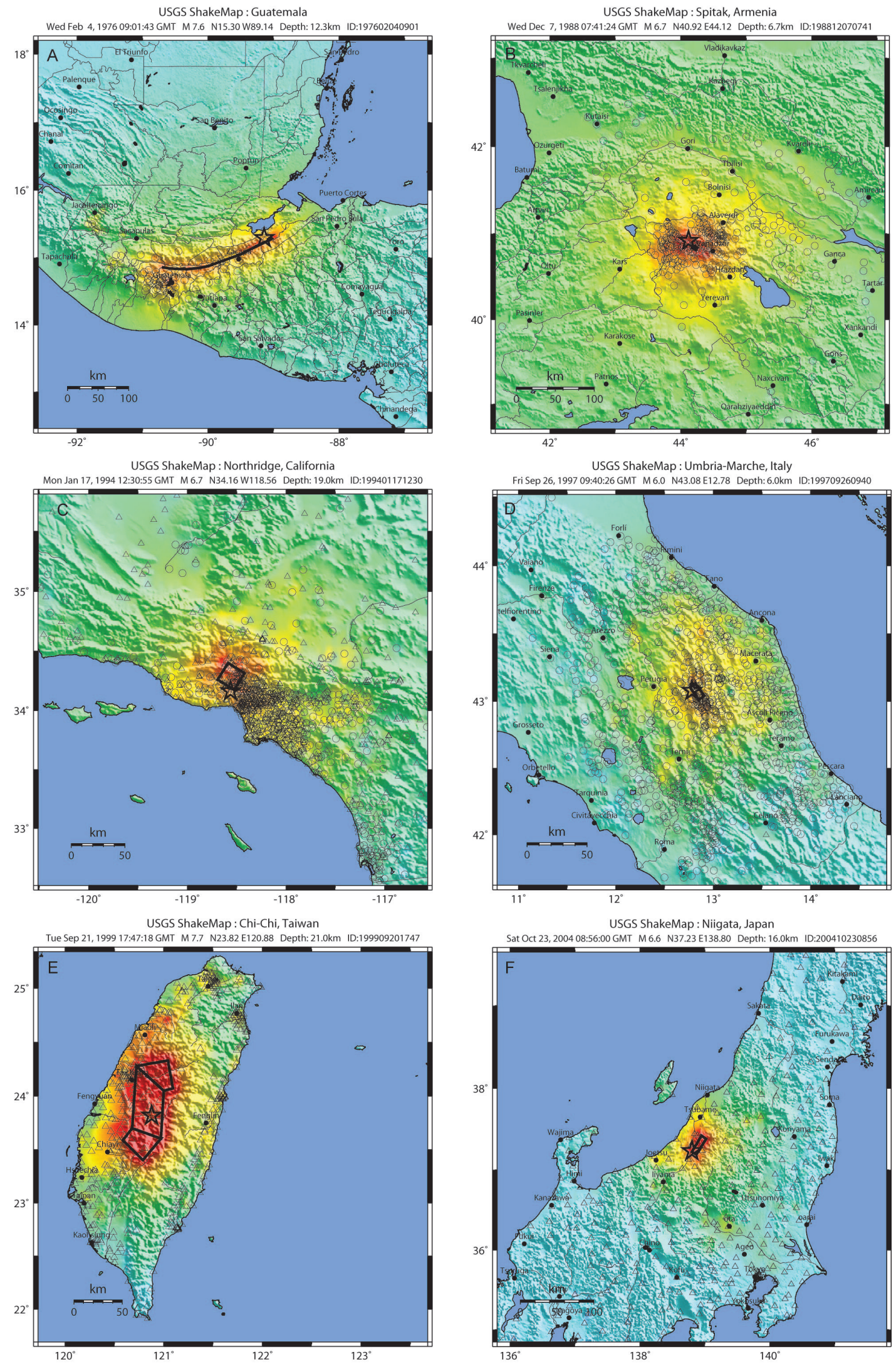

Figure 1. Some examples of ShakeMaps contained within the Atlas; $A 1976$ Guatemala, $B 1988$ Spitak, Armenia, C 1994 Northridge, California, D 1997 Umbria-Marche, Italy, E 1999 Chi-Chi, Taiwan, F2004 Niigata, Japan. $G$ indicates the standard ShakeMap color palate (Wald and others, 1999). 
G

\begin{tabular}{|c|c|c|c|c|c|c|c|c|c|}
\hline $\begin{array}{c}\text { PERCEIVED } \\
\text { SHAKING }\end{array}$ & Not felt & Weak & Light & Moderate & Strong & Very strong & Severe & Violent & Extreme \\
\hline $\begin{array}{c}\text { POTENTAL } \\
\text { DAMAGE }\end{array}$ & none & none & none & Very light & Light & Moderate & Moderate/Heavy & Heavy & Very Heavy \\
\hline PEAK ACC.(\%g) & $<.17$ & $.17-1.4$ & $1.4-3.9$ & $3.9-9.2$ & $9.2-18$ & $18-34$ & $34-65$ & $65-124$ & $>124$ \\
\hline PEAK VEL.(cm/s) & $<0.1$ & $0.1-1.1$ & $1.1-3.4$ & $3.4-8.1$ & $8.1-16$ & $16-31$ & $31-60$ & $60-116$ & $>116$ \\
\hline $\begin{array}{c}\text { INSTRUMENTAL } \\
\text { INTENSITY }\end{array}$ & $\mathrm{I}$ & II-III & IV & V & VI & VII & VIII & IX & X+ \\
\hline
\end{tabular}

Figure 1. Some examples of ShakeMaps contained within the Atlas; $A 1976$ Guatemala, $B 1988$ Spitak, Armenia, C 1994 Northridge, California, D 1997 Umbria-Marche, Italy, E 1999 Chi-Chi, Taiwan, F2004 Niigata, Japan. G indicates the standard ShakeMap color palate (Wald and others, 1999).-Continued

Armed with an approximate estimate of population exposure for some 15,000 earthquakes, we then further reduced the size of the dataset by imposing the following criteria:

- Remove all earthquakes where population exposure to MMI VI level shaking or greater is less than 3,000 people;

- Remove all earthquakes where hypocentral depth is greater than $100 \mathrm{~km}$, except those that resulted in casualties; and

- For earthquakes of $M<6.5$, remove events with hypocentral depths greater than $45 \mathrm{~km}$, except those that resulted in casualties.

This culling process leaves 4,856 earthquakes to be included within the Atlas of ShakeMaps. Since it was not practical to seek scientific literature for all of the earthquakes in the current dataset, we have imposed some subjective criteria to target key events within the Atlas. These include systematic literature searches on earthquakes with the following characteristics:

- Earthquakes where 100 or more fatalities were observed;

- Earthquakes of magnitude $M 7.2$ and greater with intensity MMI VI and above exposure greater than one million people;

- Earthquakes of magnitude less than $M 7.2$ with intensity MMI VI and above exposure greater than 10 million people; or

- Other earthquakes where auxiliary information is well-documented and easily accessible, or earthquakes that are important to obtain global coverage (for example, 1987 Edgecumbe, New Zealand; 1989 Newcastle, Australia; 1992 Roermond, Netherlands; etc.).

Overall, these criteria yielded approximately 450 earthquakes in the online Atlas that possess auxiliary information, such as finite-fault models, macroseismic intensities, or instrumental ground-motion data to be used as shaking level constraints. In addition, for many recent events where "Did
You Feel It?" data have been acquired, these intensities were also added to the ShakeMaps. The list of calibrated ShakeMaps, including key sources of information, can be accessed in Appendix I. Given the large number of references gathered in the literature survey, an electronic bibliographic database was employed to archive information for long-term storage and retrieval. Bibliographic references for those sources are compiled in Appendix II. Finally, the complete list of 4,856 events compiled for Atlas research is available in Appendix III.

The development of hazard and loss calibration methodologies requires an iterative and updateable approach. Consequently, we envisage that the number of events in the calibration dataset will continue to increase as more historical information and new data become available.

The aforementioned literature survey was extensive and has identified significant quantities of earthquake source information, instrumental ground-motion peak amplitudes, and macroseismic intensity data, but this survey was by no means exhaustive. Consequently, we continue to seek detailed earthquake data to further constrain our estimates of ground shaking for specific events. In the literature review process, we also collect information regarding damage distribution, structural inventory and vulnerability, and the number of fatalities, injuries, and homeless for later use in PAGER loss calibrations.

\section{Earthquake Observations \& Constraints}

A basic element of the ShakeMap methodology is to allow for the combination of observed and predicted groundmotion peak amplitudes. Instrumental or macroseismic ground-motions are recorded at isolated locations within the spatial extent of the map, whereas peak-ground-motion predictions are produced on a grid using a Ground Motion Prediction Equation (GMPE). When combined, observations always outweigh predictions. Consequently, the predictions are removed from the grid in the vicinity of recordings. The inclusion of a finite fault source for large earthquakes, rather than relying on a point source, also improves the final estimate of ground shaking. Most modern GMPEs predict the ground-motion relative to the distance to the fault rupture, so the regions of highest shaking near the fault rupture are better represented. 
The accuracy of the ShakeMap Atlas is dependent on quality earthquake-source and ground-motion inputs. Finitefault information, observed intensities, and recorded strong ground motions are largely sourced from professional publications and online databases (see Appendices I and II). The systematic collection and archiving of such information for hundreds of earthquakes is a considerable task, and here we describe the approach used to populate the database. While we strive for consistent, high-quality data for the Atlas earthquakes, there is a wide variety of available observational constraints for each event. There are also obvious tradeoffs between quality and quantity of data as we progress back in time to historical events, and our need for expanding the data set to cover sufficient regions and impacts of events around the globe. For these reasons it is important to preserve links or references to original sources for each event, describe our methods of usage, and to provide indicators for data quality.

\section{Finite-Fault Dimensions}

Assigning the finite-rupture source for large earthquakes $(M>6.0)$ is important to reproduce observed ground shaking in ShakeMap ground-motion estimates. This information is sometimes available from post-earthquake surveys that include observations of surface displacement, finite-fault source inversions for the rupture dimensions and slip distribution, or more recently, from InSAR observations. In some cases, we may have inferred an approximate fault rupture extent from aftershock hypocenter distribution. When a finite-fault is used in GSM, the source of the model is documented and referenced. For smaller earthquakes $(M<6.0)$, unless defined in peer-reviewed literature, a point source is deemed sufficient to describe the location of the rupture, not because source directivity and finiteness effects were not important, but rather this information is rarely available for moderate-sized earthquakes.

The requirements for describing the earthquake source may vary depending on the GMPE used to predict the ground shaking. The range of possible source to distance measures are summarized in the Pacific Earthquake Engineering Research Center's (PEER) Next Generation Attenuation (NGA) project documentation (PEER, 2007). The more complex distanceto-rupture measures promoted by the NGA modelers over simple epicentral or hypocentral distances require a more detailed source description than is available for some of the earthquakes in the Atlas. However, where available, detailed source models have allowed us to use more refined distance measures (PEER, 2007). In general, the measures currently used in the Atlas are the so-called Joyner-Boore distance, the distance to the surface projection of the rupture area-or the distance to rupture (the nearest point on the fault rupture to the observation point).

A secondary advantage of being able to define a finitefault is that it makes the ShakeMap calculation independent of the accuracy of the hypocenter calculated from regional or teleseismic waveform data. Indeed, ground-truth rupture locations from either direct fault displacement or static deformation observations provide less uncertainty as to where the rupture occurred, and finite dimensions allow the appropriate distance measure to take precedence over the hypocentral distance measure.

An important, consolidated source for finite-fault models is provided by Martin Mai of the Swiss Seismological Service, Zurich (http://www.seismo.ethz.ch/srcmod/). Many published finite-fault source models are reformatted and made available in consistent formats. Though readily available, a review of the suitability of the models must still be made prior to usage in our ShakeMap forward modeling. For events for which multiple finite-fault source studies were available in the literature or online, we selected a single description subjectively, and documented the reference (see Appendices I and II). The dimensions for all events using finiteness for the purpose of the GMPE are preserved in the ShakeMap metadata and auxiliary files, available online.

Currently, directivity is added implicitly in the use of existing GMPEs, which average directivity effects. We anticipate adding directivity effects explicitly in the near future using multiplicative factors that can be applied directly to the GMPE ground-motions (for example, Rowshandel, 2006).

\section{Instrumental Ground Motions}

In keeping with ShakeMap procedures as well as many loss-estimation approaches (for example, FEMA, 1994), we gather ground-motion parameters of peak ground acceleration (PGA), peak ground velocity (PGV), and spectral acceleration at 3 periods $(0.3,1.0$ and $3.0 \mathrm{~s})$, in addition to macroseismic intensity. At present, macroseismic intensity values are converted to peak ground accelerations and velocity values using the inverse of the Wald and others (1999c) relations.

All significant earthquakes in the NGA (PEER, 2007) and Consortium of Organizations for Strong-Motion Observation Systems (COSMOS) databases were added to the Atlas because gathering these data was a relatively simple procedure. In addition to the NGA and COSMOS data sets, a number of other earthquakes that have been well-recorded on strong-motion instruments have also been used. These events are concentrated in high-risk regions that are now well-instrumented (for example, western U.S., Japan, Taiwan, Iran, Italy, and others). For other historical events we rely on published material to obtain information regarding strong-motion recordings. The number of instrumental (peak horizontal component) data used for calibrating the Atlas at the time of writing is summarized in Table 1. Where possible we use free-field data only. However, data indicated by an "unknown" site type in the COSMOS dataset (that is, not indicated as free field or as a site on an engineered structure) are also used. 
Table 1. Summary of instrumental (peak horizontal component) data constraining earthquakes in the Atlas of ShakeMaps, categorized by tectonic environment, for PGA, PGV and spectral acceleration at $0.3,1.0$ and 3.0 seconds.

\begin{tabular}{llllll}
\hline & PGA & PGV & PSA03 & PSA10 & PSA30 \\
\hline Active Crust & 8,527 & 7,023 & 6,810 & 6,813 & 6,797 \\
Subduction Zone & 5,926 & 5,006 & 4,929 & 4,929 & 4,926 \\
Stable Continent & 211 & 122 & 113 & 127 & 40 \\
Total & 14,664 & 12,151 & 11,852 & 11,869 & 11,763 \\
\hline
\end{tabular}

\section{Macroseismic Intensities}

Many of the events in the Atlas were not captured by strong-motion instruments, but were nonetheless well-documented with macroseismic observations. In our overall strategy for reproducing shaking levels for past events, documentation of observed shaking intensities from post-disaster surveys is an important constraint.

For macroseismic intensity, the USGS uses Modified Mercalli Intensity (MMI) assignments consistent with the approach of Dewey and others (1995). Specifically, intensity $\mathrm{XI}$ and XII are no longer assigned, and intensity X is available but has not been applied for several decades. Intensity data for many of the Atlas events were assigned MMI values in the literature. Where intensity assignments are made with Medvedev-Sponheuer-Karnik (MKS-64) or European macroseismic (EMS-98) intensity scales, we assume equivalency, and herein we make no attempt to justify this assumption.

In addition to traditional intensity assignments conducted by experts (via surveys of the affected region, from engineering and other reports, or from postal questionnaires), we also employ the "USGS Did You Feel It?" (DYFI?) system for intensity data from more recent events. The DYFI? system greatly facilitates and expedites collection of macroseismic data allowing unprecedented numbers of direct observations of shaking intensity (Wald and others, 2006b). DYFI? data have also been shown to be consistent with USGS MMI assignments over the entire range of intensities (Dewey and others, 2002), with minor differences at the lowest intensities. Not only is DYFI? information valuable for areas that experience significant damage, it is also effective in constraining moderate ground-motions at larger distances (or for smaller earthquakes) that are not damaging. Such data explicitly constrain the fact that ground-motions were not damaging, whereas traditional macroseismic data-collection approaches often fail to collect or document such observations, focusing more on higher intensity data and events with such data. The DYFI? data are invaluable to constrain many recent Atlas events, both in the U.S. (post-1999) and internationally (post-2003), particularly for areas with few seismic instruments. These intensity observations can be treated as "stations" and added directly to the output ShakeMap intensity map as observational constraints. In addition, converting these measurements to peak ground-motion amplitudes further improves contoured ground-motion ShakeMaps. DYFI? reported intensities from international earthquakes tend to be from observers in large towns or cities, providing critical ground-truth data exactly where the population is concentrated (and thus where accurate loss estimates are most important). The use of DYFI? intensities in ShakeMap is discussed further in the "Putting it all Together - Constructing a ShakeMap" section.

ShakeMap methodology also allows for a bias correction to the GMPE when sufficient data (usually greater than 6 stations or macroseismic observations) are available to ensure that the peak ground-motion predictions match the observations on average (Wald and others, 2005). Such a bias term effectively removes the inter-event bias of GMPEs normally attributed to event-to-event variability, or aleatory uncertainty.

Macroseismic data is typically available in four forms for our events, and they are of variable quality depending on the accuracy of the reported location of the assigned intensity value. Some data are provided as tabulated latitude-andlongitude intensity assignments, while others may provide city or town names which can usually be found and geocoded. The lowest level of accuracy comes from digitizing locations off an isoseismal map, and assigning ordinal intensity values based on location with respect to isoseismal lines. The number of macroseismic intensity and DYFI? data available at the time of writing are summarized in Table 2.

For macroseismic intensity data, we indicate the following quality ranking (highest-to-lowest quality) in Appendix I:

1. Assigned intensities, tabulated with latitude and longitude site locations

2. Assigned intensities with site locations digitized from historic or modern maps

3. DYFI? intensities

4. Intensities with site locations (typically local town or cities identified on a map) and intensity values digitized with respect to isoseismal contours 
Table 2. Summary of macroseismic intensity and DYFI? data constraining earthquakes in the Atlas of ShakeMaps, categorized by tectonic environment.

\begin{tabular}{lll}
\hline & MMI & DYFI? \\
\hline Active Crust & 13,847 & 843 \\
Subduction Zone & 1,946 & 1,187 \\
Stable Continent & 13,798 & 1,219 \\
Total & 29,591 & 3,249 \\
\hline
\end{tabular}

\section{Ground-Motion Estimation}

The ground-motion observations described above provide the most valuable and accurate information as to the actual level of observed ground shaking. However, these observations usually only provide an estimate of the shaking at select locations and do not indicate the full spatial extent of the shaking. Where we do not possess sufficient data to fully constrain our ShakeMaps, we must rely on Ground-Motion Prediction Equations (GMPEs) that estimate the attenuation of ground shaking as a function of magnitude, site conditions, and distance from the earthquake source. These equations largely provide ground-motions in measures of acceleration and velocity as well as spectral ordinates. Because seismic intensity is also a very valuable measure of ground shaking, various equations have been developed to convert between seismic intensity and instrumental ground-motions and its inverse (for example,
Wald and others, 1999b). We use these equations to provide maps of instrumental ground-motion intensities in ShakeMap.

The level of ground shaking is not only dependent on the distance from the earthquake source, but also upon the geology at the site. We employ global maps that use topographic slope as a proxy for seismic site-conditions (Allen and Wald, 2007; Wald and Allen, 2007) in order to estimate potential modification of ground shaking amplitudes from local site geology. Before deciding on which GMPEs and coefficients for local site conditions are used, we must first determine what tectonic regime the earthquake has occurred in; ground-motion attenuation and estimates of local site conditions (based on topography) are dependent on the tectonic regime (Wald and Allen, 2007). Below, we explain for our choice of groundmotion modeling methods for the ShakeMap Atlas in more detail.

\section{Tectonic Regime}

We use three broad categories for defining which tectonic environment an earthquake has occurred in; shallow active tectonic crust, subduction zone (both interplate and intraslab), and stable continent. As described above, the choice of tectonic regime determines which GMPE and site condition coefficients are used to predict ShakeMap ground-motions. Figure 2 provides a logic tree approach to our definitions of tectonic environment. The first step in the logic is to decide whether the earthquake has occurred in a stable continental region (SCR). Stable continental regions are typically characterized by lower attenuation than seismically active regions (for example, Bakun and McGarr, 2002; Atkinson and Wald, 2007) and thus require different GMPEs to describe the

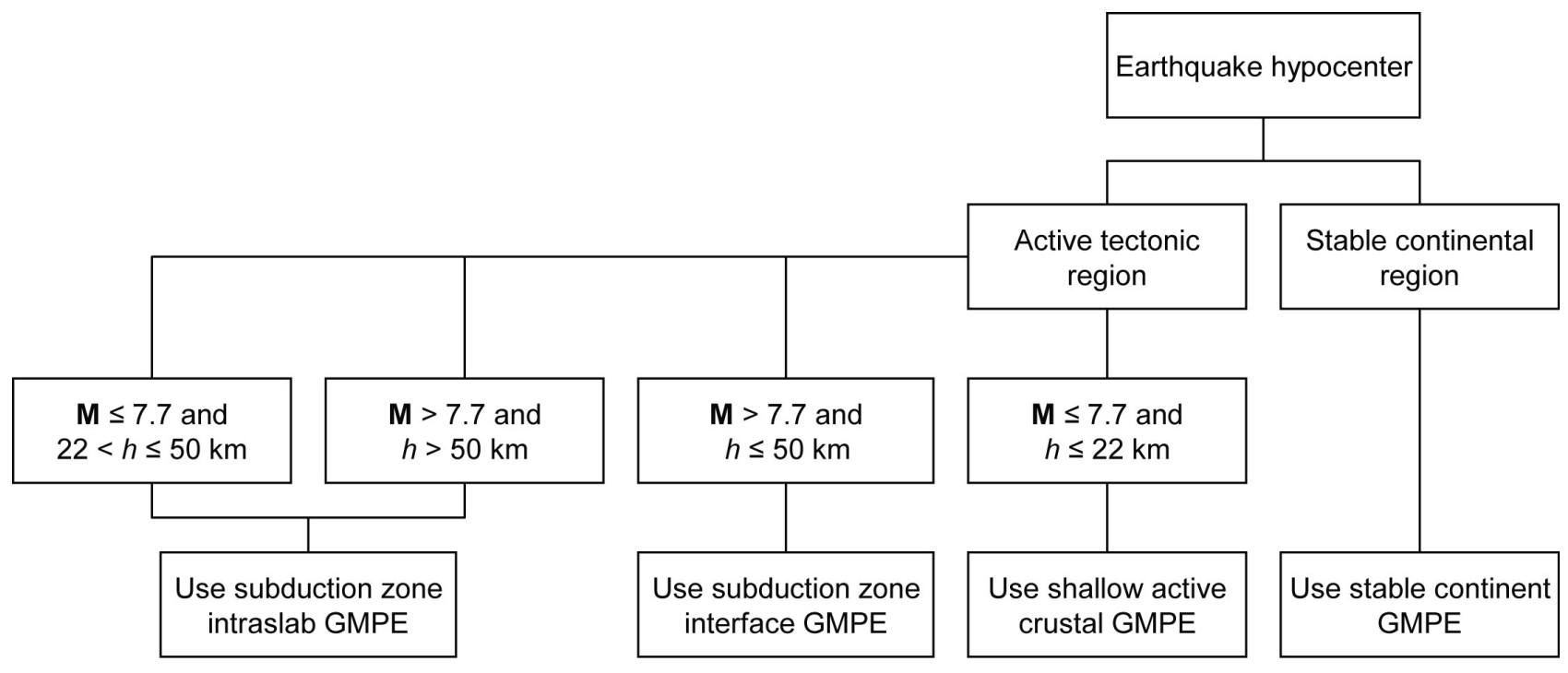

Figure 2. Logic tree defining default tectonic environment from earthquake location and source parameters. 
ground-motion. In a report prepared for the Electric Power Research Institute, Johnston and others(1994) provided maps of global SCRs. These maps were digitized in a Geographical Information Systems (GIS) framework and used to classify earthquakes in the Atlas as originating in either active crust or stable continent (fig. 3).

If an earthquake has occurred in an active tectonic region, the next step is to choose whether it took place in shallow crust or within a subduction zone. Our default configurations are designed to separate events in these tectonic regimes based on their magnitude and depth (fig. 2). However, this configuration can break down in some instances, and the GMPE must be manually reconfigured. For example, the $2002 M_{\mathrm{w}} 7.9$ Denali, Alaska earthquake, which was a large shallow crustal, strikeslip event, would be allocated a subduction-zone setting based on the default configurations. Fortunately, these events are relatively rare in the Atlas and are usually well documented.

\section{Relationships between Peak Ground-Motions and Intensities}

With the expansion of digital strong-motion networks and the advent of online MMI reporting (for example, DYFI?), the number of co-located MMI observations and ground-motion records has increased dramatically. These MMI data can be correlated with nearby strong-motion recording stations to provide MMI-strong-motion relations. Consequently, several relationships that seek to calibrate shaking intensity with measures of peak ground-motion have been developed over the past decade (Sokolov and Chernov, 1998; Wald and others, 1999b; Atkinson and Sonley, 2000; Kaka and Atkinson, 2004; Atkinson and Kaka, 2007). The current ShakeMap algorithm for mapping intensity from peak ground-motions employs a combination of PGA and PGV, with the former being used for lower intensities, transitioning to PGV for higher intensities (Wald and others, 1999c).

\section{Ground-Motion Prediction Equations Used}

Once we have decided which tectonic environment an earthquake has occurred in, we then select an appropriate GMPE to predict the ground-motions over the spatial extent of the ShakeMap not already constrained by observed groundmotions. For application in GSM, we require that the GMPEs allow for calculation of PGA, PGV and spectral acceleration values at periods of $0.3,1.0$ and 3.0 seconds. Most modern relations satisfy these conditions, but a number of earlier studies provide either one or only a subset of these parameters as predictive variables. In the case where PGV is not explicitly defined, $1 \mathrm{~Hz}$ spectral acceleration (converted to velocity) is commonly used as a proxy for PGV (Newmark and Hall, 1982). This is the logic we have adopted in our analysis for any GMPEs that lack PGV coefficients.

The GMPEs currently used in GSM are Boore and others (1997), Youngs and others (1997), and Atkinson and
Boore(2006) for active crust, subduction zones, and stable continent tectonic regimes, respectively. However, the abundant ground-motion and macroseismic data gathered for events around the globe will allow us to render judgment on the applicability of currently used GMPEs, in addition to other modern relations, an effort currently under investigation. Consequently, we expect the default configuration of GMPEs to change in the near future, with the possible need to apply modifiers to some GMPEs (including NGA relations) so that they are applicable at larger distance ranges.

\section{Regional Site Response Corrections}

Prediction of site-specific ground-motions from GMPEs relies on the assignment of a local site response factor, generally derived from the average shear velocity over the upper 30 meters $\left(V_{S}^{30}\right)$. Because this is now standard practice (for example, Building Seismic Safety Council, 2004), we require a first-order estimate of $V_{S}^{30}$ for all regions around the globe in order to estimate reliable ground-motions.

Wald and Allen (2007) describe a technique to derive first-order site condition maps directly from topographic data. Taking the gradient of the regional topography and choosing the ranges of slope that maximize the correlation with shallow shear-velocity observations, this method can recover, to first order, seismic site-condition maps that are of similar quality to site class maps developed from surficial geology and $V_{S}^{30}$ measurements by other researchers around the world (for example, Wills and others, 2000; Bauer and others, 2001; Lee and others, 2001; Matsuoka and others, 2005).

Wald and Allen (2007) developed two sets of correlations for deriving $V_{S}^{30}$ from topographic slope; one for active tectonic regions where variations in topographic relief are large, and one for stable continents where topography is more subdued. For example, in Figure 4 we show the seismic site conditions of the active tectonic region of the San Francisco Bay Area, which possesses an abundance of $V_{S}^{30}$ measurements. Figure $4 A$ illustrates the topographic relief of the region, which is superimposed with $V_{S}^{30}$ measurements color-coded by their $V_{S}^{30}$ value. We compare the geologically derived $V_{S}^{30}$ map of Wills and others (2000) (fig. $4 B$ ) with the map derived from the slope of topography (fig. $4 C$ ). Note the $V_{S}^{30}$ values around the San Francisco Bay area vary widely, but they do so with rather systematic trends that are wellrecovered using topographic slope. Figure $4 D$ indicates the relative differences of the predicted amplification derived from the Borcherdt (1994) relations assuming a uniform PGA of $250 \mathrm{~cm} / \mathrm{s}^{2}$ for the geologically- and topographically-based $V_{S}^{30}$ maps. The ratio of amplifications for the two maps in the San Francisco Bay area indicates little difference in amplification around the bay itself. However, the topographically-based $V_{S}^{30}$ map predicts consistently higher amplification in the Central Valley in the northeast margin of the map, because the $V_{S}^{30}$ estimates in this area are lower in the topographically-based than the geologically-based of Wills and others (2000). 


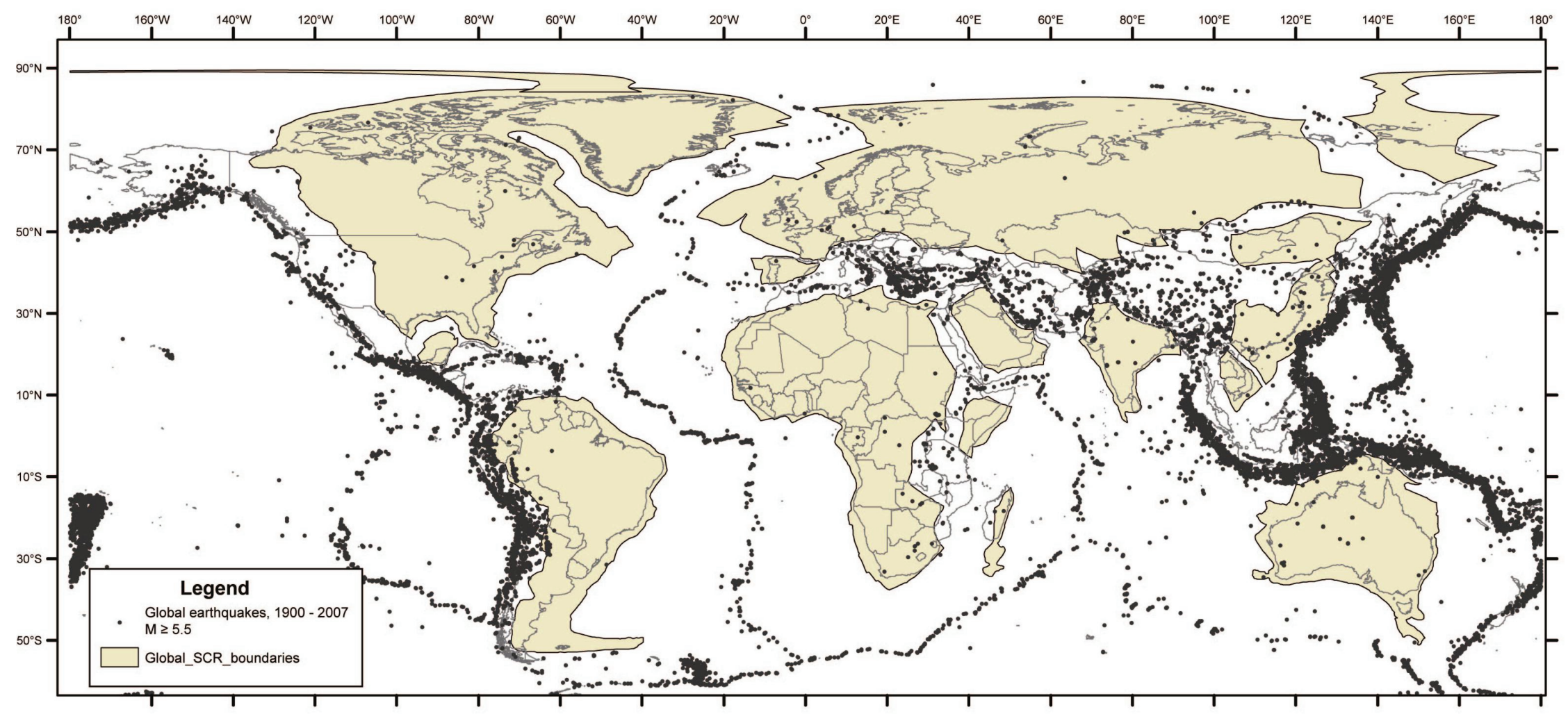

Figure 3. Global stable continental regions digitized from Johnston and others (1994) superimposed with earthquake epicenters from PAGER-CAT (see http://earthquake.usgs.gov/research/data/pager/). 

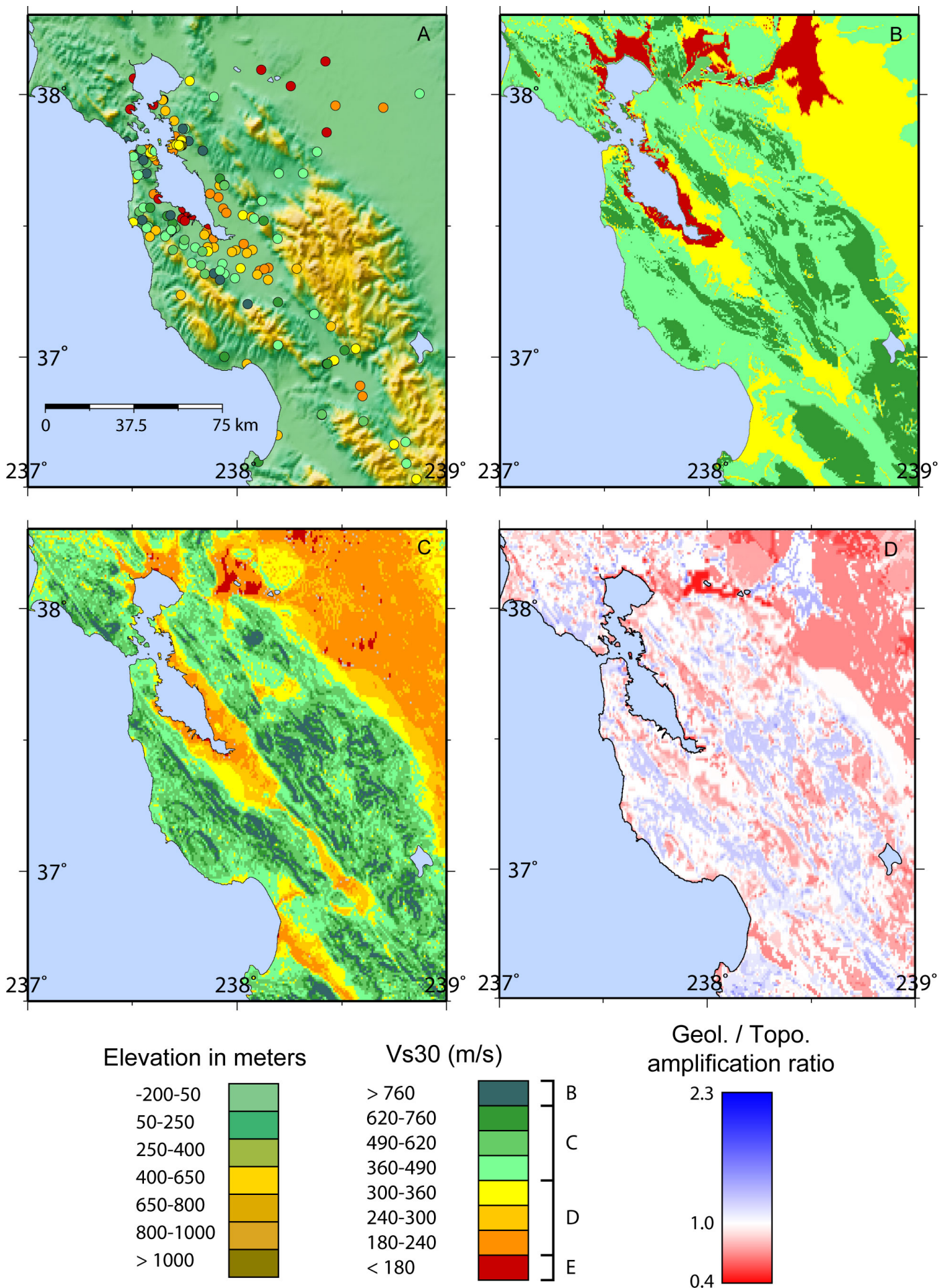

Figure 4. A, Topographic map of the San Francisco Bay Area. Circles indicate the location of $V_{S}^{30}$ measurements, color-coded by shear-wave velocity in $\mathrm{m} / \mathrm{s}$ (see middle legend). $B$, Seismic sitecondition map based on geology and $V_{S}^{30}$ observations (modified from Wills and others, 2000). $C$, Sitecondition map derived from topographic slope. $D$, The ratio of the predicted amplification for a uniform PGA of $250 \mathrm{~cm} / \mathrm{s}^{2}$ for the geologically- and topographically-based $V_{s}^{30}$ maps. Blues indicate that the Wills and others (2000) map predicts higher amplification, whereas reds indicate higher amplifications are predicted from the topographically-based map. White indicated where the two $V_{s}^{30}$ maps predict the same amplification. 
On a global scale, the slope-based approach proposed by Wald and Allen (2007) provides a simple, objective approach to uniform site-condition mapping (Allen and Wald, 2007). Development of a higher-resolution global topographic database and corresponding slope-derived $V_{S}^{30}$ values is under investigation (Allen and Wald, 2008). Basin structures are acknowledged as being a significant contributor to groundmotion amplification, but we are presently unable to consider these effects using current ShakeMap methodology, particularly on a global scale.

\section{Putting it all Together-Constructing a ShakeMap}

Above we have discussed the key elements that are necessary for constructing a ShakeMap. We now present step-by-step examples of the evolution of a ShakeMap for the 2007 Central Peru earthquake, the 1997 Umbria-Marche main shock, and finally, the 2006 Kythira, Greece earthquake.

The 15 August $2007 M_{\mathrm{w}} 8.0$ Pisco earthquake off the coast of central Peru caused widespread damage in the region and resulted in over 500 fatalities. An unconstrained ShakeMap of this earthquake is shown in Figure $5 \mathrm{~A}$. The distance measure used to calculate the ground-motions in this case is estimated by rotating random fault geometries (of appropriate length) about the earthquake epicenter and subsequently calculating a median distance to this fault. This leads to an underestimation of the fault-to-site distance in regions not near the actual fault rupture which, results in overall higher groundshaking estimates in these areas. In contrast, sites closest to the actual rupture will underestimate the true ground shaking because the source-to-site distance is maximized. Adding the DYFI? data to the ShakeMap provides reliable estimates of the shaking in the population centers, where constraining the ground-shaking is most important (fig. $5 B$ ). However, in ShakeMap we only calculate an inter-event bias correction if a finite-fault is explicitly defined, or if the earthquake is below a certain magnitude threshold where fault finiteness can, in effect, be ignored. The current configuration allows a bias term to be calculated for all events less than $M_{\mathrm{w}} 7.0$ that have some measure of ground-motion; it is not appropriate to compute a bias in cases where the observation station-to-fault distances cannot be computed due to lack of knowledge of the fault location. Incorporating the finite-fault into the ShakeMap for the 2007 Peru event, we see that the regions of higher ground shaking now extend further to the southeast, commensurate with the length and orientation of the estimated fault (fig. $5 C$ ). In contrast, ground-motions further to the northwest decrease slightly owing to an overall larger source-to-site distance being used to calculate the ground shaking. Combining the fault and DYFI? intensity data now provides a better constrained ShakeMap for this event, allowing for an inter-event bias term to be calculated. In this case, the bias term for PGV is again relatively small having a multiplicative factor of 1.05 .
The previous example of a ShakeMap's evolution is essentially what can be achieved in near-real-time with the automatic assignment of DYFI? data, coupled with rapid finite-fault estimation methods. However, for most of the events in the Atlas, we must go back to historical records and literature to find the necessary calibration information. Below, we give an example of this using the 26 September $1997 M_{\mathrm{w}}$ 6.0 Umbria-Marche, Italy earthquake. Figure $6 A$ shows the unconstrained ShakeMap as a simple point source event. A finite fault (Hernandez and others, 2004) was added to the ShakeMap and resulted in an overall larger area being exposed to strong ground shaking (fig. 6B). Some strong-motion data were gathered for the 1997 event from the NGA dataset and these were subsequently added to the ShakeMap (fig. 6C). Incorporation of these data resulted in a slight increase in shaking in the epicentral region. An abundance of macroseismic intensity data were collected following this event by the Istituto Nazionaledi Geofisica e Vulcanologia (INGV), Italy and these were added to the ShakeMap (fig. 6D). Such dense data coverage results in less reliance on the original GMPE since most of the shaking in the ShakeMap is now defined by actual observations and the prediction equations are only used on the periphery of the map where observations are absent. Abundant data such as this enables us to capture aleatory ground-shaking effects more readily. The Umbria-Marche event presents a best-case scenario for Atlas events, since most events comprise a small fraction of the data used to constrain the shaking of this earthquake. However, intensity data that have been collected for the Atlas enable us to calibrate many historical ShakeMaps better than could be achieved using ground-motion prediction equations alone.

The two previous events demonstrate the importance of being able to define intensities where human exposures are most dense. However, neither of these events strongly demonstrate the use of macroseismic data for correcting the interevent ground shaking bias. Here we examine the 8 January $2006 M_{\mathrm{w}} 6.7$ Kythira Island, Greece earthquake. Damage from this event was limited to the islands of Kythira and Antikythira, in addition to some locations in western Crete (Konstantinou and others, 2006). ShakeMap ground-motions were first estimated using the Youngs and others (1997) GMPE combined amplifications derived from Wald and Allen's (2007) global seismic site-condition maps (fig. 7A). Predicted ground-motions in this unconstrained ShakeMap would suggest that potentially damaging ground-motions would have occurred near Neapoli Voion on the Epidavros Limira Peninsula. However, when we add the macroseismic data from Konstantinou and others (2006), we observe that ground shaking on the mainland of Greece is significantly diminished, while ground-motions on the island of Kythira remained high (fig. 7B). Overall, the ground-motions were reduced by approximately 40 percent from the base ground-motions predicted by the Youngs and others (1997) GMPE. This suggests that the attenuation of strong ground-motion in the subduction zone to the south of Greece may be higher than that predicted by the GMPE. As such, an inter-event bias correction provided 

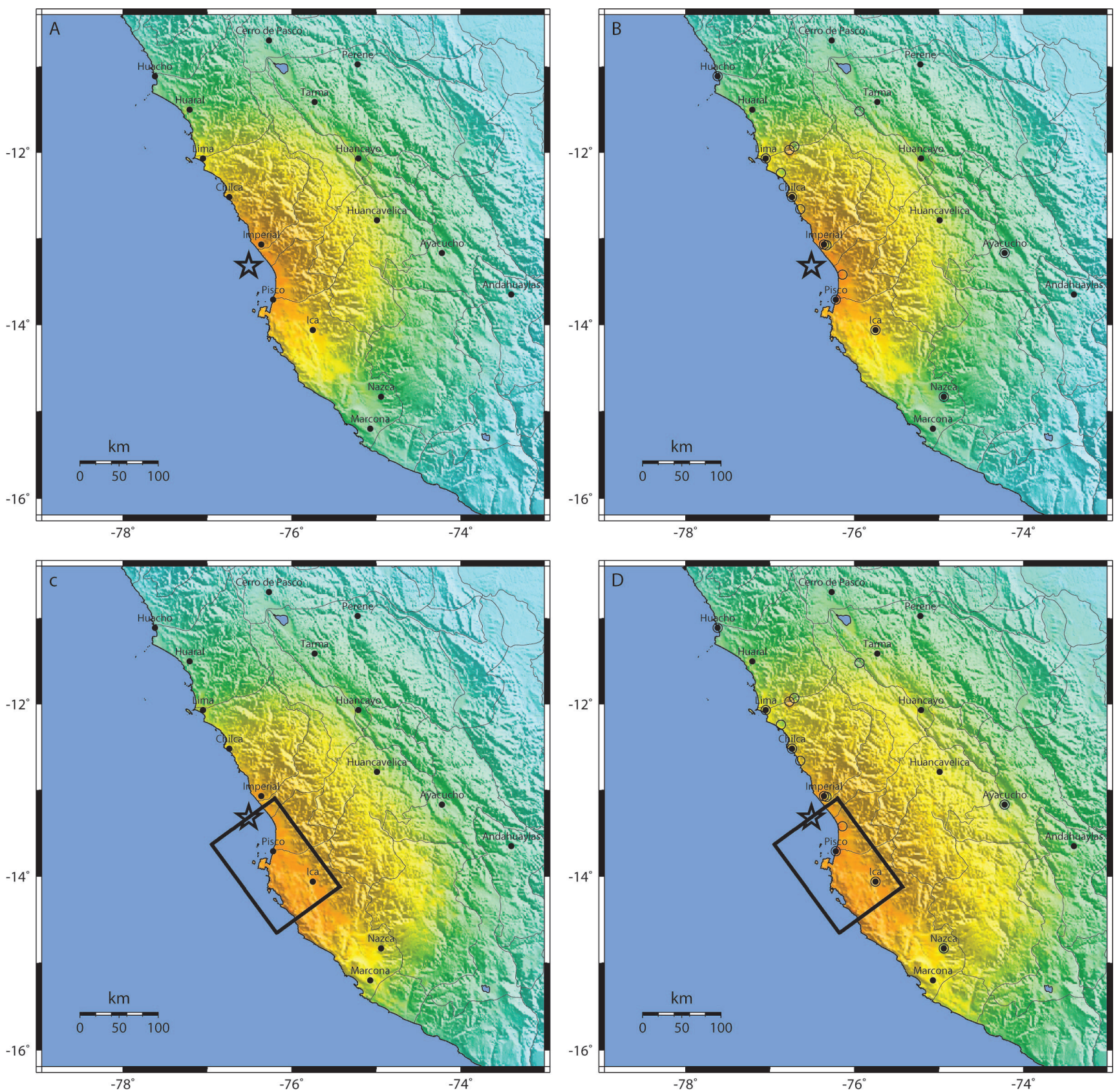

Figure 5. Evolution of the Pisco, Peru earthquake 15 August $2007 M_{w} 8.0$ ShakeMap. $A$ ShakeMap contrained with the earthquake hypocenter and magnitude only. $B$ Addition of DYFI? intensity data. $C$ Finite fault combined with earthquake hypocenter and magnitude. $D$ Combination of finite fault and DYFI? 

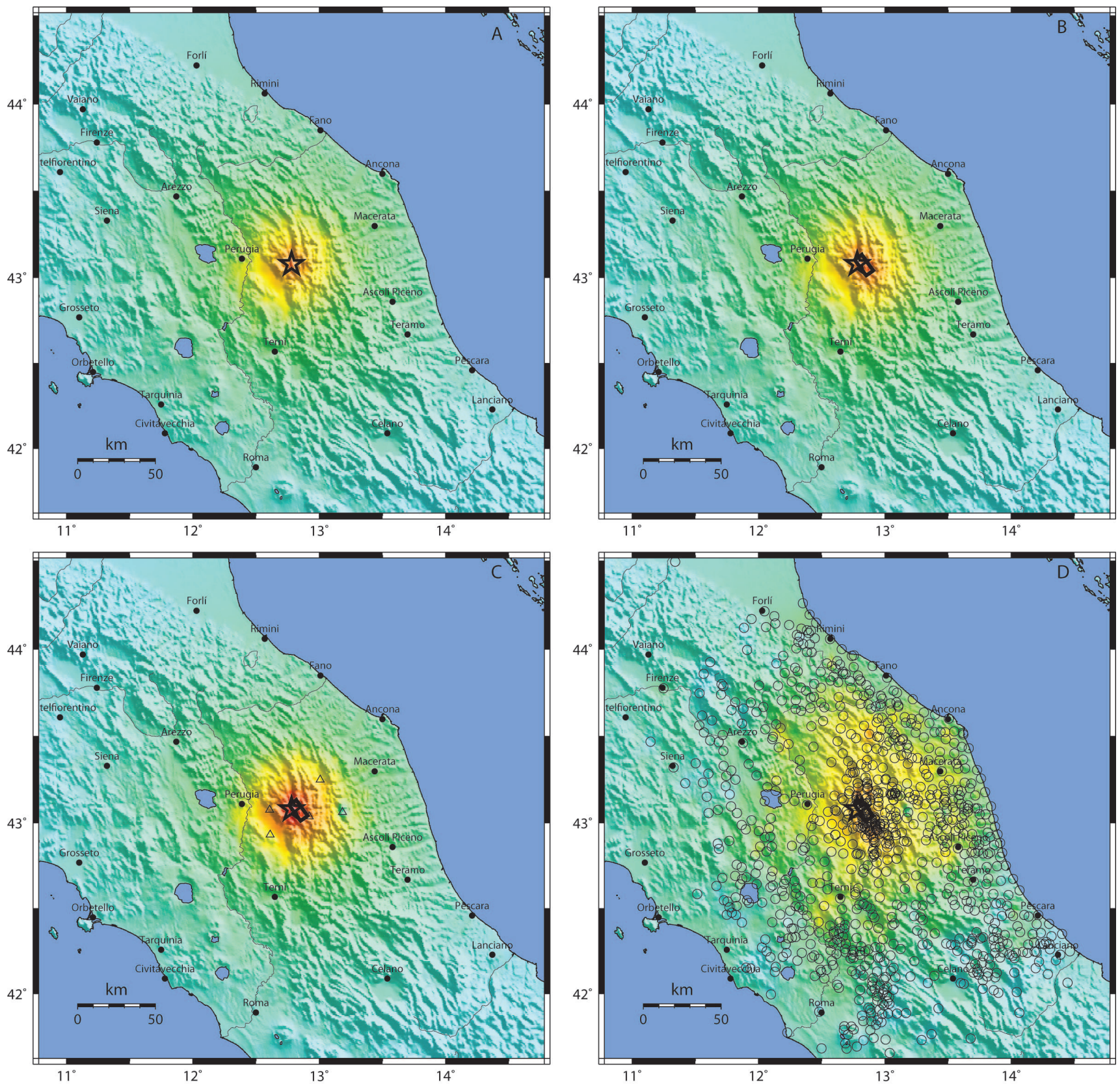

Figure 6. Evolution of the ShakeMap for the 26 September $1997 M_{W} 6.0$ Umbria-Marche, Italy earthquake. $A$ ShakeMap constrained with the earthquake hypocenter and magnitude only. $B$ Addition of the finite fault of Hernandez and others (2004). C Finite fault combined with recorded strong motion data. $D$ Combination of finite fault, strong motion and macroseismic intensity data collected by the INGV. 

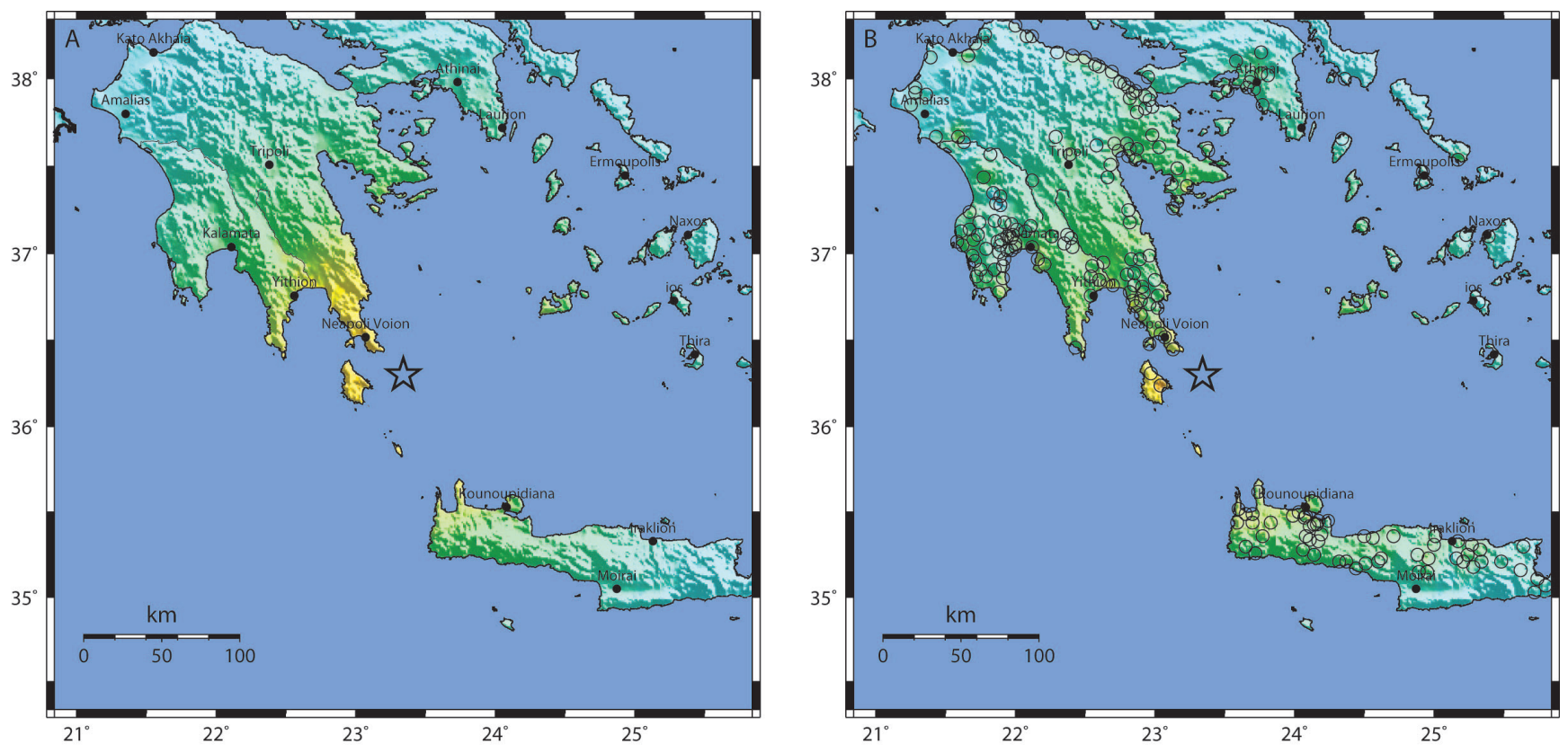

Figure 7. Evolution of the ShakeMap for the 6 January $2006 M_{w} 6.7$ Kythira Island, Greece earthquake. A ShakeMap contrained with the earthquake hypocenter and magnitude only. B Addition of the macroseismic intensity data (open circles) from Konstantinou and others (2006).

by online DYFI? reports may be an important constraint for future events in the region where we may initially overestimate the ground shaking, and the subsequent loss estimates, if we rely on predictive ground-motion equations such as Youngs and others (1997).

\section{Quantifying Ground-Motion Uncertainties}

Although ShakeMaps developed for the Atlas and those used in near-real time for the PAGER system are sometimes constrained by rapidly gathered ground-motion and intensity data via the Internet, and/or with rupture dimensions resolved with rapid finite-fault analyses, they are still fundamentally predictive. These factors, plus the systematic estimation of site amplification on a global basis, all add uncertainties. Fortunately, many of these uncertainties can be quantified, and here we discuss efforts to quantify the ShakeMap spatial uncertainty. As discussed below, uncertainty information can be used on a point-by-point basis, or to characterize the overall quality of an event's ShakeMap, providing users with a relative quality weight for use in hazard and loss modeling applications. It is important to note that in this analysis we do not consider the epistemic uncertainty between various ground-motion models, though often relative differences among models are accommodated with the event-bias term (Wald and others, 2005, 2008) Furthermore, the gridded uncertainty values are a relative multiplier to the uncertainty of the GMPE used.

\section{Quantitative Shaking Uncertainty Calculations}

The uncertainty of a given ShakeMap varies spatially over the map area and depends on a number of contributing factors (Lin and others, 2005). However, it is usually dominated by two factors: (1) spatial variability of peak groundmotions near intensity observations or recording stations, and (2) the aleatory uncertainty associated with the GMPE used to fill in station gaps. Here, we summarize these two sources of variability in estimating ShakeMap uncertainty. This methodology is documented more thoroughly in Wald and others (2008). It should be noted that we have not considered the contribution of uncertainty of both hypocenter location and magnitude to ground-motion uncertainty. Both of these are significant issues for the near real-time Global ShakeMaps which rely on preliminary event information, but are less so for the historic and reviewed data used in the Atlas.

Spatial variability of peak ground-motions can be generalized in the form of a rapidly increasing uncertainty with increasing distance from the nearest recording station or macroseismic observation. Additional uncertainty arises from estimating ground-motions from the GMPE. This uncertainty in ground-motion prediction is increased due to initial, unconstrained source-rupture dimensions, particularly for large earthquakes (about $M_{\mathrm{w}} 6.0$ and greater). The uncertainty is highest for larger magnitude earthquakes when source finiteness is not yet constrained and, hence, the site-to-source distance is also uncertain. Not knowing the true distance to the fault rupture contributes significant uncertainty, particularly in the near-fault region, and this uncertainty scales with magnitude. 
Our goal in quantifying ShakeMap uncertainty is to produce a spatial grid that contains not only the various peak ground-motion parameters at each point, but also the variance at that point for each ground-motion parameter. For generating a map of uncertainty values at each grid point, we consider the cases described below. It is important to note that the gridded uncertainty values are uncertainty multipliers to the sigma of the GMPE used in the ShakeMap.

The least reliable ShakeMaps in our Atlas are those that do not possess any ground-motion data or finite-fault constraints. As mentioned above, we assume that earthquake locations and magnitudes are correct, although these parameters can lead to significant uncertainties of their own. This being acknowledged, for small-to-moderate magnitude earthquakes where point-source representation is sufficient, the uncertainty near the source is equivalent to the sigma of the GMPE used (fig. 8A). However, if ground-motion data exist, then the uncertainty at a grid point is controlled by its proximity to the nearest station (10 km or less) as defined by Boore and others (2003). The spatial variability in ground-motions thus reduces to zero as the distance between known and unknown sites decreases to zero (fig. $8 B$ ).

For earthquakes where a point source is not sufficient to describe the ground shaking and no finite-fault is defined, the spatial distribution of uncertainty becomes more complex. Because many GMPEs use a site's distance to the fault rupture or surface projection of the fault, we must incorporate additional uncertainty into our ground-shaking estimate. This is because we do not know the dimensions or orientation of the fault rupture. Consequently, we adopt the results and the approach defined in an Electric Power Research Institute (2003) report, in which the distance adjustment is determined for the case where the rupture orientation is assumed to be uniformly distributed in azimuth from 0 to 360 degrees and for a combination of strike-slip and reverse ruptures using random epicenters. Hence, when the fault geometry and orientation are not known, a median value of ground motion at each point is provided rather than the simple epicentral distance-based estimation. While this approach is currently used for ShakeMap, it tends to underestimate ground motions near a finite fault (since it uses the maximum possible source-station distance) rather than providing a mean value based on random fault geometry and epicenter. Since we have some confidence in the fault location at the epicenter, the uncertainty at that point is controlled by the sigma of the GMPE. Moving away from the epicenter, the uncertainty is given by the EPRI relations and increases immediately adjacent to the epicenter and gradually decreases with distance (fig. $8 C$ ). The level of uncertainty increases as the magnitude increases owing to the increasing dimensions of the fault. If ground-motion data exist, then the uncertainty of the map is zero at the station, but then follows the relations of Boore and others (2003) at distances less than $10 \mathrm{~km}$ from the site (fig. $8 D$ ).

In the case that we have a fault dimensions, but no additional ground-motion data, then the uncertainty is uniform across the whole ShakeMap and is equal to the sigma of the
GMPE (fig. 8E). Although the finite-fault itself may be an approximation only, we assume that the fault definition is sufficient and that all uncertainty in the ShakeMap is derived from the GMPE. The most reliable ShakeMaps are those that comprise both significant numbers of ground-motion data (instrumental and/or macroseismic) and an estimate of the fault rupture. Where there are stations, the uncertainty is reduced to zero, and elsewhere the uncertainty is equivalent to that of the GMPE (fig. $8 F$ ).

\section{Qualitative Uncertainty Assignments}

For each ShakeMap in the Atlas, we provide a letter grade (A-F) as to the quality of the map. The grade is based on the average uncertainty of the ShakeMap at onshore sites of MMI VI and above. The grading scale is derived rather subjectively by assessing the mean uncertainty, with the highest grades being assigned to those earthquakes for which we have high confidence that the ShakeMap is representative of the observed shaking. Lower grades are assigned to those events that are less well constrained and have higher values of mean uncertainty, with the lowest grades given to those events with large magnitudes that do not have additional constraints. The grading scale is defined in Table 3 and each example in Figure 8 is assigned an uncertainty letter grade. These grades are useful in providing a relative weighting of the Atlas events in loss calibration analyses.

\section{ShakeMap Atlas Products}

Many previous studies on earthquake vulnerability and loss have relied on variable approaches to map hazard. Consequently, deficiencies in ground-motion descriptions were often propagated through to error in loss estimates and the two would be hard to separate. In fact, many studies rely on simple point-source descriptions, ignore depth variations or site conditions, and greatly simplify ground-motion attenuation with distance to the source (for example, Chen and others, 1997; Samardjieva and Badal, 2002; Nichols and Beavers, 2003). In

Table 3. Uncertainty grading scale used in GSM.

\begin{tabular}{ll}
\hline Grade & Mean Uncertainty Factor \\
\hline A & $>0.96$ Sigma \\
B & $0.96-0.98$ Sigma \\
C & $0.98-1.05$ Sigma \\
D & $1.05-1.25$ Sigma \\
F & $>1.25$ Sigma \\
\hline
\end{tabular}



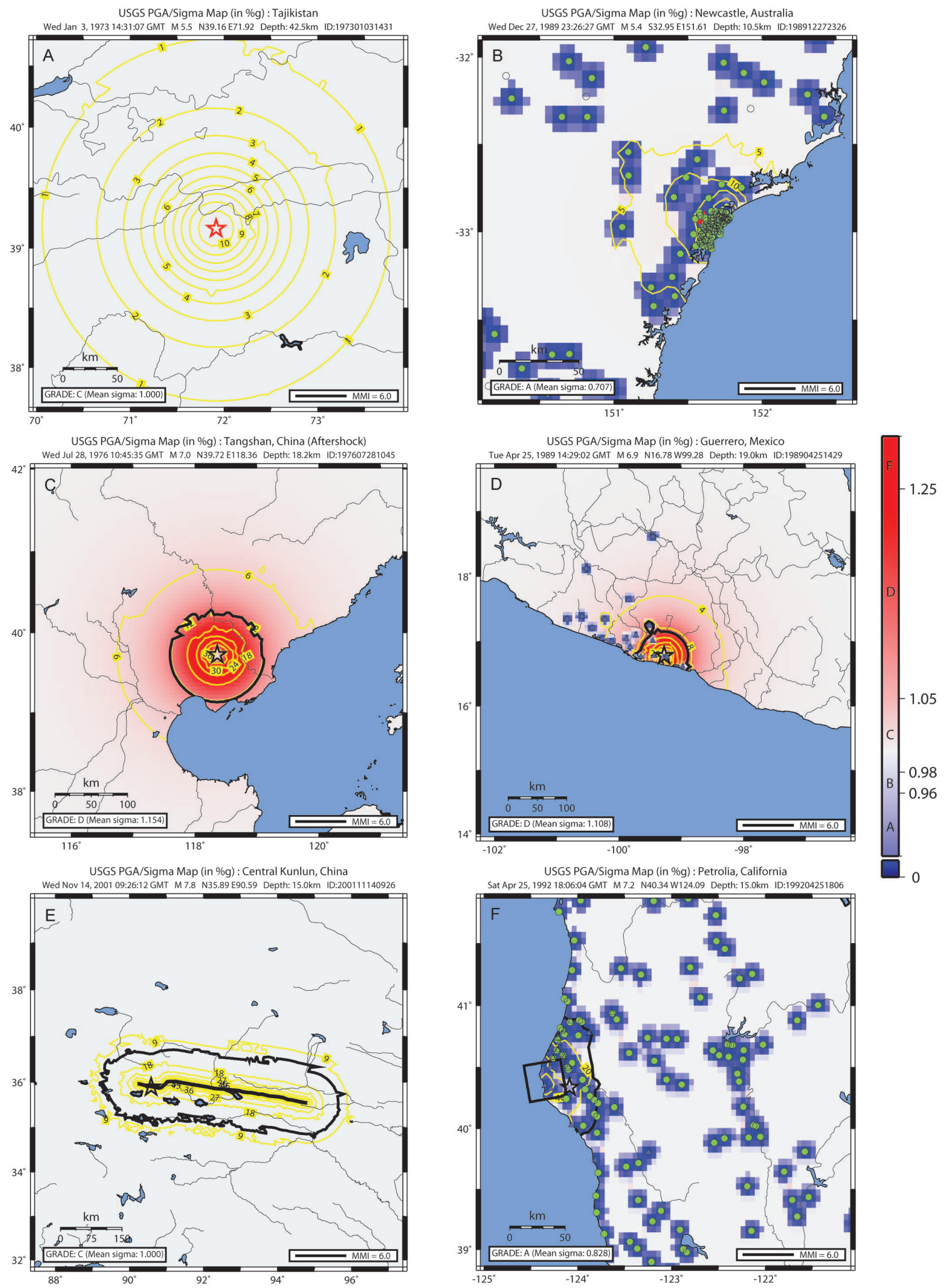

Figure 8. Examples of ShakeMap uncertainty grids for the cases of; $A$ moderate-sized event where point source representation is sufficient with no additional data; $B$ moderate-sized point source event with additional ground-motion data; $C$ large earthquake with no data constraints; $D$ large earthquake with some ground-motion data and no fault; $E$ large earthquake with finite-fault representation and no additional ground-motion data and; $F$ large earthquake with both finite-fault and ground-motion data constraints. The thick black contours enclose the regions of $\mathrm{MMI} \mathrm{VI}$ and greater, and an uncertainty letter grade is given in the lower left corner of each map. 
contrast, studies that have been performed using a systematic approach to mapping hazard are often not openly available. A primary benefit of employing the ShakeMap system for generating the Atlas is the production of a consistent set of maps for each earthquake, each generated with well-accepted and documented procedures. A secondary benefit of this approach is the uniformity of output hazard products, ranging from GIS maps, HAZUS (FEMA, 1994) specified input files, and Extensible Markup Language (XML) formatted grid output files containing parametric data and uncertainties for all points on each ShakeMap. The range of consistent products for each event provides a benchmark for loss modeling, response and mitigation analyses, in addition to other research efforts.

Here we describe these products in brief. A more detailed description can be found both online (http://earthquake.usgs. gov/shakemap/) and in the ShakeMap Manual (Wald and others, 2005). Since the Atlas will be updated regularly with additional earthquakes, going both forward and backward in time, we plan to release an updated version, approximately yearly. We also outline our plans for updating the Atlas and associated databases using version control.

The Atlas ShakeMap web pages are built from the template for existing ShakeMap pages. The Atlas events are given a separate Archive, allowing (as for other ShakeMaps) subsets of maps to be sorted by either date or country. Once finding the ShakeMap pages for a specific event, the products are consistent with any online ShakeMap (Wald and others, 2005). ShakeMaps produced by regional U.S. networks will be retained in their present state and key events will be duplicated in the Atlas, reflecting the difference in near-real time ShakeMaps versus ShakeMaps augmented with later obtained auxiliary data such as fault dimensions and macroseismic observations.

The Atlas web pages and maps are also interactive. Selection of individual stations (triangles) or macroseismic observations (circles) on the map initializes a pop-up lookup table that provides station and macroseismic data information, including names, locations, coordinates, the peak ground-motion values recorded on each component, or the reported intensity. As described earlier, if the reported data were ground-motion recordings, then we also report the inferred intensity; if the data were originally macroseismic intensity, the inferred peak ground-motions are reported. The Web interface thus provides a convenient format for obtaining detailed strong-motion information for specific sites.

For each ShakeMap, all maps and associated products for that event are available on the earthquake-specific Web pages as described below. The link provided at the bottom of a ShakeMap's Download page entitled Product Formats provides detailed background for each of the map and product formats available. Products available for download are: maps of instrumental intensity, PGA, PGV, peak spectral values, and uncertainty; raw data grids; a list of stations used in the ShakeMap with their location and peak motions; GIS files (for example, ArcGIS shapefiles); and KML files for use in Google Earth.
Version 1.0 of the online version of the Atlas was "frozen" in time once uploaded. As we further enhance the Atlas, a new version will be put online, but only after significant revision and additional events warrant a new release. At that time, changes from the earlier version will be documented and the prior version will be archived. We will allow for easy visual comparison of the maps from one version to the next so that users can easily identify significant changes to the maps.

As the Atlas is updated, future revisions may include several enhancements to Version 1.0, including:

- Addition of recent events and more historical events.

- Employ revised global $V_{S}^{30}$ grid with higher resolution Shuttle Radar Topography Mission (Farr and Kobrick, 2000) topography data.

- For those events with source-rupture models, the rupture dimensions will be available for download in detailed XML and text formats, commensurate with the rupture models available in the literature.

- Updated GMPEs, possibly modified to predict groundmotions over larger distances.

- Rupture induced directivity will be added explicitly using the approach of Rowshandel (2006).

- Fitting simple functions or shapes (for example, ellipses) to hill-basin interfaces, derived from change in slope, whose aspect ratios could provide an estimate of basin location, orientation, and depth.

- Enhanced intensity-to-ground-motion conversions. For example:

- Invert Wald and others(1999b) data to solve for PGM given MMI data (for example, Gerstenburger and others, 2008)

- Add magnitude and distance dependence to Wald and others $(1999 b)$ relations

- Use of Bayes Theorem to estimate PGM given MMI as well as magnitude and distance (Ebel and Wald, 2003)

\section{Composite Global ShakeMap}

Finally, armed with almost 5,000 ShakeMaps of significant earthquakes, we have created a composite ShakeMap to provide a global perspective of earthquake ground shaking from January 1973 to September 2007. The ShakeMaps are combined to give the maximum PGA experienced at a particular location (fig. 9A). This map can be compared to the Global Seismic Hazard Map (GSHAP; fig. 9B) (Giardini and others, 1999). While both the Atlasbased and GSHAP maps were derived with a similar catalogue 

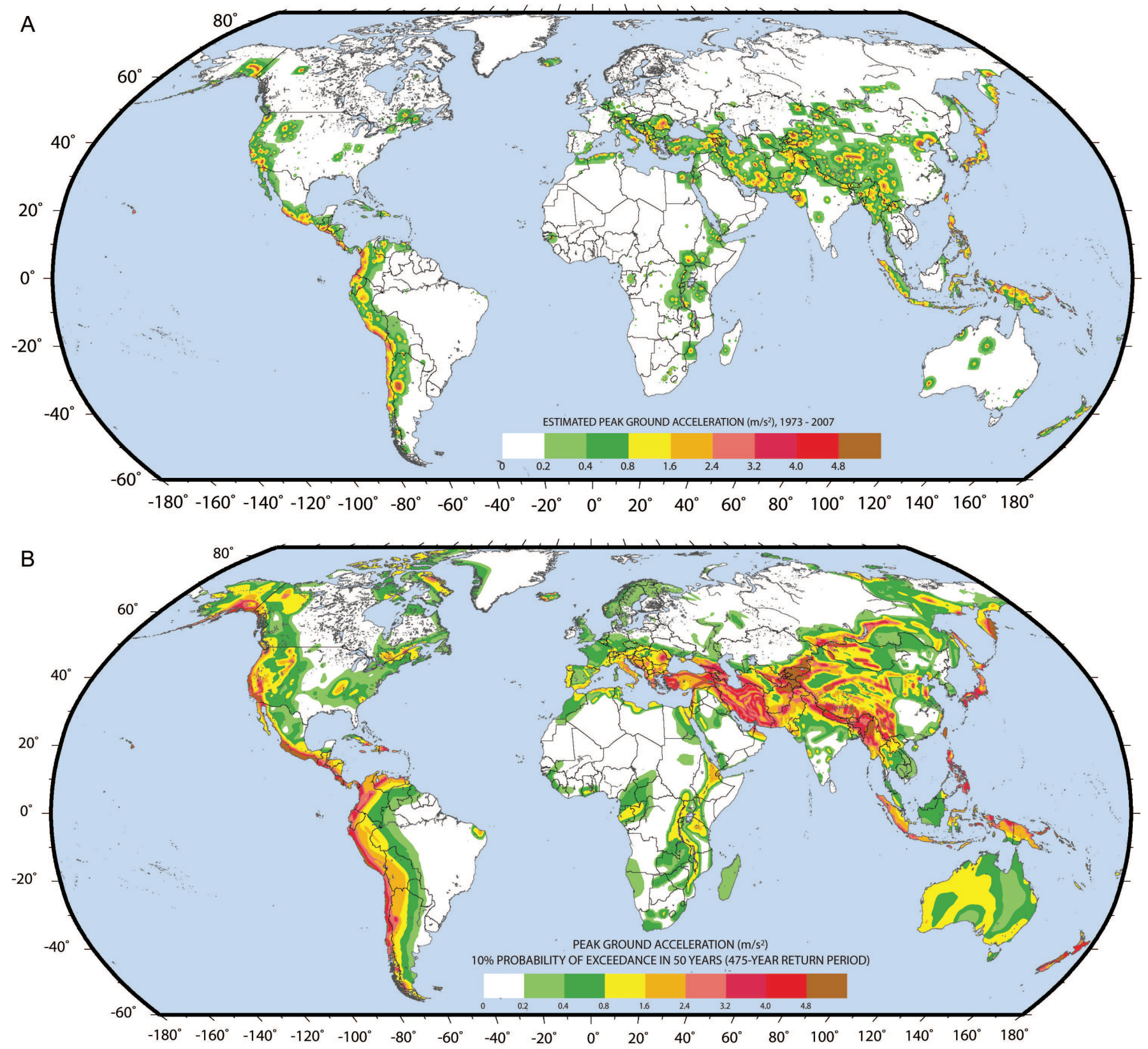

Figure 9. A Combined Atlas ShakeMaps indicating the maximum PGA estimated at any location in the World (near significant population exposure) for earthquakes $M \geq 5.5$ from 1973 to September 2007, and B the Global Seismic Hazard Map (GSHAP), which indicates a 10 percent chance of exceedance in 50 years (after Giardini and others, 1999). 
of historical seismicity prior to 1999 , the Atlas represents hazard due to events that have actually occurred since 1973 (approximately 35 years) and is not influenced by earthquake recurrence estimates, tectonic strain rates, palaeoseismological or geomorphological investigations, or geodetic constraints. Additionally, unlike the GSHAP map, the Atlas-based map was produced with a uniform approach to ground-motion estimation, includes data and additional source constraints, and also incorporates amplification from topographicallybased seismic site conditions. In contrast, GSHAP used more variable approaches to characterize the hazards from region to region.

With this information, we are able to quantitatively compare the two maps. We do this by finding the ratio of the GSHAP map of 10 percent chance of exceedance in 50 years relative to the composite ShakeMap PGA map. Given that the ShakeMap Atlas represents approximately 35 years of global ground shaking, we would expect approximately 7 percent of the global landmass to have exceeded the GSHAP hazard. Oceanic areas that have ground-motions and hazard associated with them are masked from the comparisons. There are some important conditions that must be recognized prior to evaluating these results. Because the Atlas was designed primarily to support the development of loss estimation methodologies, we only include earthquakes that have significant population exposure to moderate levels of ground shaking. Furthermore, we only include earthquakes of magnitude 5.5 and greater, unless the earthquake resulted in fatalities. These factors may lead to an underestimation in the observed PGA in some regions that have only experienced small, non-damaging earthquakes (for example, eastern North America). Consequently, the total area of our composite map to have exceeded the assigned PGA hazard in GSHAP should be an underestimate (that is, less than 7 percent), since we do not consider full global coverage or lower magnitude events. Another important consideration is that our composite ShakeMap includes the effects of uniform global site response (Wald and Allen, 2007), whereas the GSHAP hazard map provides bedrock hazard only. This effect should act to slightly increase the predicted ground-motion, and subsequently, the spatial area on the composite ShakeMap exceeding GSHAP.

Figure 10 indicates the percentage ratio of our composite ShakeMap PGA map against the GSHAP map for South America. Values of lower than, equal to, or above, 100 percent represent where the composite map is lower, equal to, or exceeds the GSHAP map, respectively. Table 4 summarizes the percentage area of landmass that has exceeded GSHAP hazard for map regions compiled by Grünthal and others (1999), McCue (1999), Shedlock and Tanner (1999), and Zhang and others (1999). Other key regions that are well constrained in the Atlas are considered separately (for example, California, Japan and Turkey). We do not attempt to make any qualitative assessments on these results. We note that in some regions the composite ShakeMap does appear to reflect a percentage area exceeding GSHAP near 7 percent (for example, Africa, Continental Asia and Japan). However, predicted hazard in other regions appears conservative relative to observed activity over the past 35 years (for example, Australia, SW Pacific and SE Asia, and the Americas). A possible explanation may be that some probability of a large earthquake or earthquakes was factored into hazard calculations and these events that have not been observed in modern times. Note, that the $2004 M_{W} 9.0$ Sumatra-Andaman Islands earthquake and tsunami only affected a small fraction of the landmass in the Australia, SW Pacific and SE Asia hazard map (McCue, 1999) in terms of actual ground shaking. Consequently it only had a minor effect on the spatial area of the map that exceeded GSHAP.

Because there are many events within the Atlas that have no data constraints, we acknowledge that there may be some uncertainty associated with purely predictive groundmotions. However, many of the largest events in the catalogue that exceed GSHAP hazard are indeed well-constrained with finite-fault models and some information regarding the level of ground shaking.

\section{Conclusion}

The primary motivation for the development of the Atlas of ShakeMaps has been for the subsequent development of PAGER loss methodologies (for example, Jaiswal and others, 2008; Porter and others, 2008). However, development of the Atlas has also provided incentive to implement several improvements to the Global ShakeMap system itself. The key improvements and related research are summarized as:

- More precise polygons indicating stable continental and active tectonic regions digitized from the maps of Johnston and others (1994).

- Introduction of modern Ground Motion Prediction Equations (for example, Atkinson and Boore, 2006; Boore and Atkinson, 2007) and quantitative evaluation of each model against observed global data.

- Improved estimates of uniformly-derived seismic-site conditions $\left(V_{S}^{30}\right)$ for the globe.

- Routine calculation of ShakeMap uncertainty

- Improved download documentation with the introduction of the "info.xml" file which indicates precise information regarding the input parameters used for the current ShakeMap (that is, GMPE used, bias applied to GMPE predictions for each ground-shaking type, fault file used, mean uncertainty, and map grade).

An unexpected benefit of the Atlas is that it has proven beneficial for developing experience and confidence in modeling hundreds of significant earthquakes, skills useful for the real-time response to future global earthquakes. This experience, together with knowledge of fault rupture models from other historical earthquakes in any chosen region, can 

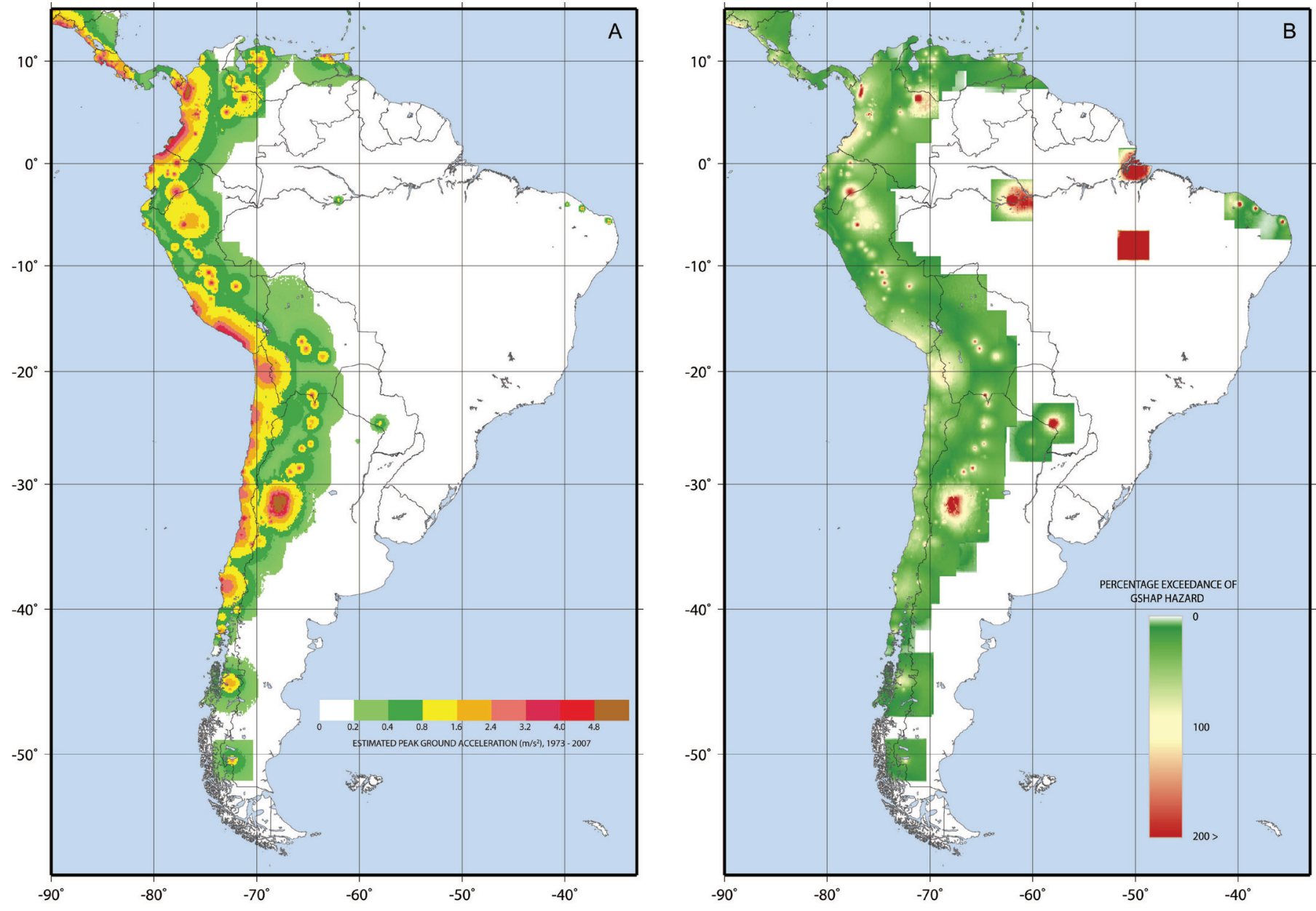

Figure10. A Combined PGA for Atlas ShakeMaps for South America, and $B$ the percentage exceedance of the estimated PGA from 1973 to September 2007 relative to the GSHAP 10 percent in 50 year hazard map for South America. Values greater than 100 percent represent regions where PGA on the GSHAP hazard map have been exceeded.

assist in rapid assessment of the expected ground shaking and impact using GSM. In response to the recent $M_{W} 7.7$ Chilean earthquake on 14 November, 2007, we were able to rapidly and successfully approximate the earthquake fault rupture by referencing historical ruptures in the Atlas and subsequently estimate the expected ground shaking before finite-fault inversions were available or aftershocks had occurred to help constrain the extent of the rupture. A further benefit derived from the Atlas includes a quantitative approach to evaluate global and regional earthquake-hazard maps employing our composite PGA map based on a catalogue of 35 years of global seismicity. We can also estimate the number of times a certain hazard level has been exceeded at any grid point.

The collection of significant quantities of global groundmotion data has prompted us to reevaluate the GMPEs used in the Global ShakeMap system. As discussed previously, the current configuration of GSM employs Boore and others (1997), Youngs and others (1997) and Atkinson and Boore (2006) for active crust, subduction zones and stable continent tectonic regimes, respectively. Over the past few years, several new relations that seek to predict ground motions in different tectonic environments have been developed through the NGA project (PEER, 2007) and other studies. We are currently quantitatively assessing the applicability of several well known GMPEs against Atlas ground-motion data for their application in GSM. In addition to the currently configured GMPEs listed above, they also test several other relations in active crust (Sadigh and others, 1997; Chiou and Youngs, 2006; Kanno and others, 2006; Boore and Atkinson, 2007; Campbell and Bozorgnia, 2007), subduction zones (Atkinson and Boore, 2003; Kanno and others, 2006; Lin and Lee, 2008) and stable continental regions (Atkinson and Boore, 1997; Toro and others, 1997; Campbell, 2003). We are also investigating the possible need to modify GMPEs that have limitations in predicting ground-motions beyond 100 or $200 \mathrm{~km}$. Along with corrections to GMPEs comes the need to modify PGM-MMI relations based on their distance residuals, coupled with possible differences in residuals owing to tectonic regime.

While the ShakeMaps are generated using a systematic approach, quality of the maps does vary; they are only as 
Table 4. Percentage of landmass exceeding the GSHAP hazard map for different regions in the world from January 1973 to September 2007.

\begin{tabular}{llc}
\hline Region & \multicolumn{1}{c}{$\begin{array}{c}\text { Map bounds } \\
\text { (lon1/lon2/lat1/lat2) }\end{array}$} & $\begin{array}{c}\text { Percentage of } \\
\text { landmass } \\
\text { area exceeded }\end{array}$ \\
\hline Africa & $-20 / 55 /-36 / 38$ & 7.0 \\
Australia, SW Pacific \& SE Asia & $93 / 180 /-48 / 20$ & 2.5 \\
California \& Nevada & $-124.5 /-114 / 32.5 / 42.05$ & 2.3 \\
Conterminous United States \& Mexico & $-126 /-63 / 15 / 50$ & 2.0 \\
Continental Asia & $60 / 150 / 0 / 60$ & 6.3 \\
Europe & $-10 / 45 / 35 / 56$ & 4.5 \\
Japan & $128 / 146 / 30 / 46$ & 13.1 \\
North America & $-180 /-30 / 15 / 72$ & 1.1 \\
South America & $-90 /-33 /-57 / 15$ & 2.6 \\
Turkey & $25.67 / 44.82 / 35.81 / 42.10$ & 4.2 \\
Global Average & $-180 / 180 /-60 / 84$ & 3.6 \\
\hline
\end{tabular}

reliable as the data and direct observations, site conditions, GMPEs, and other input constraints used to generate them. Consequently, we continue to seek robust earthquake data to update and improve our predictive capacity of ground shaking for future earthquakes.

Though developed primarily for the PAGER project, we anticipate other uses for the historical ShakeMap Atlas, including disaster response, scenario planning, mitigation, and outreach programs. The updateable, fully documented online version of the ShakeMap Atlas will also facilitate direct comparison of loss estimates for alternative loss methodologies against a systematically-derived set of ShakeMap hazard inputs and outputs.

\section{Acknowledgments}

Development of the ShakeMap Atlas benefited from the availability of the NGA database as well as the finite-fault database developed by Martin Mai (ETH, Zurich). Jim Dewey and Margaret Hopper provided macroseismic data input and advice. Other key data sources used include COSMOS, K-NET, the ESD, the NGDC, CERESIS, and the INGV. We are also thankful to Clive Collins, Frank Scherbaum, Mark Stirling and Gail Atkinson for additional seismic-intensity data. Faulting, ground-motion, and intensity constraints used herein are the aggregated sum of numerous post-earthquake reconnaissance reports, published earthquake studies, and strong-motion monitoring network efforts, all of which help build a comprehensive view of individual events. Citations to these sources are found in Appendices I and II. Reviews by Mary-Lou Zoback and Chuck Mueller helped to improve this report. Funding for this research was provided in part by a grant from USAID. Figures 1 and 4-10 were produced using Generic Mapping Tools (Wessel and Smith, 1991).

\section{References Cited}

Allen, T.I., and Wald, D.J., 2007, Topographic slope as a proxy for seismic site-conditions $\left(V_{S}^{30}\right)$ and amplification around the globe: U.S. Geological Survey Open-File Report 2007-1357, 69 p.

Allen, T.I., and Wald, D.J., 2008, Evaluation of the use of high-resolution topographic data as a proxy for seismic site conditions $\left(V_{S}^{30}\right)$ : Seism. Res. Lett., v. 79, no. 2, p. 277.

Atkinson, G.M., and Boore, D.M., 1997, Some comparisons between recent ground-motion relations: Seism. Res. Lett., v. 68 , no. 1 , p. 24-40.

Atkinson, G.M., and Boore, D.M., 2003, Empirical groundmotion relations for subduction-zone earthquakes and their application to Cascadia and other regions: Bull. Seism. Soc. Am., v. 93, no. 4, p. 1703-1729. 
Atkinson, G.M., and Boore, D.M., 2006, Earthquake groundmotion predictions for eastern North America: Bull. Seism. Soc. Am., v. 96, p. 2181-2205.

Atkinson, G.M., and Kaka, S.I., 2007, Relationships between felt intensity and instrumental ground motion: Bull. Seism. Soc. Am., v. 97, no. 2, p. 497-510.

Atkinson, G.M., and Sonley, E., 2000, Relationships between Modified Mercalli Intensity and response spectra: Bull. Seism. Soc. Am., v. 90, p. 537-544.

Atkinson, G.M., and Wald, D.J., 2007, "Did You Feel It?" intensity data: A surprisingly good measure of earthquake ground motion: Seism. Res. Lett., v. 78, no. 3, p. 362-368.

Bakun, W.H., and McGarr, A., 2002, Differences in attenuation among the stable continental regions: Geophys. Res. Lett., v. 29, no. 23.

Bauer, R.A., Kiefer, J., and Hester, N., 2001, Soil amplification maps for estimating earthquake ground motions in the Central US: Eng. Geol., v. 62, p. 7-17.

Bhaduri, B., Bright, E., Coleman, P., and Dobson, J., 2002, LandScan-locating people is what matters: Geoinformatics, v. 5, no. 2, p. 34-37.

Boore, D.M., and Atkinson, G.M., 2007, Boore-Atkinson NGA ground motion relations for the geometric mean horizontal component of peak and spectral ground motion parameters: Berkeley, Calif., Pacific Earthquake Engineering Research Center, 234 p.

Boore, D.M., Gibbs, J.F., Joyner, W.B., Tinsley, J.C., and Ponti, D.J., 2003, Estimated ground motion from the 1994 Northridge, California, earthquake at the site of the Interstate 10 and La Cienega Boulevard Bridge collapse, West Los Angeles, California: Bull. Seism. Soc. Am., v. 93, no. 6, p. 2737-2751.

Boore, D.M., Joyner, W.B., and Fumal, T.E., 1997, Equations for estimating horizontal response spectra and peak acceleration from Western North American earthquakes: A summary of recent work: Seismological Research Letters, v. 68 , no. 1 , p. $128-153$.

Borcherdt, R.D., 1994, Estimates of site-dependent response spectra for design (methodology and justification): Earthquake Spectra, v. 10, no. 4, p. 617-653.

Building Seismic Safety Council, 2004, NEHRP Recommended Provisions for seismic regulations for new buildings and other structures, 2003 edition: Federal Emergency Management Agency 450, 338 p.
Campbell, K.W., 2003, Prediction of strong ground motion using the hybrid empirical method and its use in the development of ground-motion (attenuation) relations in eastern North America: Bull. Seism. Soc. Am., v. 93, no. 3, p. 1012-1033.

Campbell, K.W., and Bozorgnia, Y., 2007, Campbell-Bozorgnia NGA ground motion relations for the geometric mean horizontal component of peak and spectral ground motion parameters: Berkeley, Calif., Pacific Earthquake Engineering Research Center, 240 p.

Chen, Q.-F., Chen, Y., Liu, J., and Chen, L., 1997, Quick and approximate estimation of earthquake loss based on macroscopic index of exposure and population distribution: Nat. Hazards, v. 15, p. 217-222.

Chiou, B.S.-J., and Youngs, R.R., 2006, PEER-NGA empirical ground motion model for the average horizontal component of peak acceleration and psuedo-spectral acceleration for spectral periods of 0.01 to 10 seconds; Interim report for USGS review: Richmond, Calif., Pacific Earthquake Engineering Research Center, Interim Reports of Next Generation Attenuation (NGA) Models, 219 p.

Dewey, J.W., Hopper, M.G., Wald, D.J., Quitoriano, V., and Adams, E.R., 2002, Intensity distribution and isoseismal maps for the Nisqually, Washington, earthquake of 28 February 2001: Open-File Report, v. U.S. Geological Survey, no. 02-0346, p. 57 pp.

Dewey, J.W., Reagor, B.G., Dengler, L., and Moley, K., 1995, Intensity distribution and isoseismal maps for the Northridge, California, earthquake of January 17, 1994: U.S. Geological Survey Open-File Report, v. 95-92, p. 35.

Dobson, J.E., Bright, E.A., Coleman, P.R., Durfee, R.C., and Worley, B.A., 2000, LandScan: A global population database for estimating populations at risk: Photogrammetric Engineering \& Remote Sensing, v. 66, no. 7, p. 849-857.

Dziewonski, A.M., Chou, T.-A., and Woodhouse, J.H., 1981, Determination of earthquake source parameters from waveform data for studies of global and regional seismicity: J. Geophys. Res., v. 86, no. B4, p. 2825-2852.

Ebel, J.E., and Wald, D.J., 2003, Bayesian estimations of peak ground acceleration and 5\% damped spectral acceleration from modified Mercalli intensity data: Earthquake Spectra, v. 19 , no. 3 , p. 511-529.

Electric Power Research Institute, 2003, CEUS ground motion project: model development and results: Palo Alto, Calif., Electric Power Research Institute.

Engdahl, E.R., van der Hilst, R., and Buland, R., 1998, Global teleseismic earthquake relocation with improved travel times and procedures for depth determination: Bull. Seism. Soc. Am., v. 88, no. 3, p. 722-743. 
Farr, T.G., and Kobrick, M., 2000, Shuttle Radar Topography Mission produces a wealth of data: EOS Trans., v. 81, p. 583-585.

FEMA, 1994, NEHRP recommended provisions for the development of seismic regulations for new buildings, FEMA, v. Part 1 -provisions, $290 \mathrm{p}$.

Gerstenburger, M.C., Worden, C.B., and Wald, D.J., 2008, Using online felt report data to derive a probabilistic relationship between MMI and ground shaking amplitude: Seism. Res. Lett, v. 79, no. 2, p. 314.

Giardini, D., Grünthal, G., Shedlock, K.M., and Zhang, P., 1999, The GSHAP global seismic hazard map: Ann. Geofis., v. 42, no. 6, p. 1225-1230.

Grünthal, G., Bosse, C., Sellami, S., Mayer-Rosa, D., and Giardini, D., 1999, Compilation of the GSHAP regional seismic hazard for Europe, Africa and the Middle East: Ann. Geofis., v. 42, no. 6, p. 1215-1223.

Hernandez, B., Cocco, M., Cotton, F., Stramondo, S., Scotti, O., Courboulex, F., and Campillo, M., 2004, Rupture history of the 1997 Umbria-Marche (central Italy) main shocks from the inversion of GPS, DInSAR and near field strong motion data: Ann. Geophys.-Italy, v. 47, no. 4, p. $1355-1376$.

Jaiswal, K.S., Wald, D.J., and Porter, K.A., 2008, Development of a global, semi-empirical approach for rapid estimation of human casualties due to earthquakes: Seism. Res. Lett., v. 79, no. 2, p. 314.

Johnston, A.C., Coppersmith, K.J., Kanter, L.R., and Cornell, C.A., 1994, The earthquakes of stable continental regions, Volume 1-Assessment of large earthquake potential: Palo Alto, Calif., Electric Power Research Institute.

Kaka, S.I., and Atkinson, G.M., 2004, Relationships between instrumental ground-motion parameters and Modified Mercalli Intensity in eastern North America: Bull. Seism. Soc. Am., v. 94, no. 5, p. 1728-1736.

Kanno, T., Narita, A., Morikawa, N., Fujiwara, H., and Fukushima, Y., 2006, A new attenuation relation for strong ground motion in Japan based on recorded data: Bull. Seism. Soc. Am., v. 96, no. 3, p. 879-897.

Konstantinou, K.I., Kalogeras, I.S., Melis, N.S., Kourouzidis, M.C., and Stavrakakis, G.N., 2006, The 8 January 2006 earthquake $\left(M_{w} 6.7\right)$ offshore Kythira Island, southern Greece: seismological, strong-motion, and macroseismic observations of an intermediate-depth event: Seism. Res. Lett., v. 77 , no. 5, p. 544-553.

Lee, C.-T., Cheng, C.-T., Liao, C.-W., and Tsai, Y.-B., 2001, Site classification of Taiwan free-field strong-motion stations: Bull. Seism. Soc. Am., v. 91, p. 1283-1297.
Lin, K.-W., Wald, D.J., Worden, B.C., and Shakal, A.F., 2005, Quantifying CISN ShakeMap Uncertainty, in CSMIP '05 Seminar on the Utilization of Strong Motion Data, p. 37-49.

Lin, P.-S., and Lee, C.-T., 2008, Ground-motion attenuation relationships for subduction-zone earthquakes in northeastern Taiwan: Bull. Seism. Soc. Am., v. 98, no. 1, p. 220-240.

Matsuoka, M., Wakamatsu, K., Fujimoto, K., and Midorikawa, S., 2005, Nationwide site amplification zoning using GISbased Japan engineering geomorphologic classification map, International Conference on Structural Safety and Reliability, 9, Rome, Italy, June 19-23, 2005, Proceedings: Rotterdam, Netherlands, Millpress, p. 239-246.

McCue, K., 1999, Seismic hazard mapping in Australia, the southwest Pacific and southeast Asia: Ann. Geofis., v. 42, no. 6, p. 1191-1198.

Newmark, N.M., and Hall, W.J., 1982, Earthquake spectra and design: Berkeley, CA, Earthquake Engineering Research Institute.

Nichols, J.M., and Beavers, J.E., 2003, Development and calibration of an earthquake fatality function: Earthquake Spectra, v. 19, no. 3, p. 605-633.

Pacific Earthquake Engineering Research Center, 2007, Next generation attenuation of ground motions (NGA) project: Berkeley, no. http://peer.berkeley.edu/products/nga_project. html, Accessed October 26, 2007.

Porter, K.A., Wald, D., Allen, T., and Jaiswal, K., 2008, An empirical relationship between fatalities and instrumental MMI for PAGER: Seism. Res. Lett., v. 79, no. 2, p. 314.

Rowshandel, B., 2006, Incorporating source rupture characteristics into ground motion hazard analysis models: Seism. Res. Lett., v. 77, no. 6, p. 708-722.

Sadigh, K., Chang, C.Y., Egan, J.A., Makdisi, F., and Youngs, R.R., 1997, Attenuation relationships for shallow crustal earthquakes based on California strong motion data: Seism. Res. Lett., v. 68, no. 1, p. 180-189.

Samardjieva, E., and Badal, J., 2002, Estimation of the expected number of casualties caused by strong earthquakes: Bull. Seism. Soc. Am., v. 92, no. 6, p. 2310-2322.

Shedlock, K.M., and Tanner, J.G., 1999, Seismic hazard map of the western hemisphere: Ann. Geofis., v. 42, no. 6, p. 1199-1214.

Sipkin, S.A., Person, W.J., and Presgrave, B.W., 2000, Earthquake bulletins and catalogs at the USGS National Earthquake Information Center: IRIS Newsletter, v. 2000, no. 1, p. 2-4. 
Sokolov, V.Y., and Chernov, Y.K., 1998, On the correlation of seismic intensity with Fourier amplitude spectra: Earthquake Spectra, v. 14, no. 4, p. 679-694.

Toro, G.R., Abrahamson, N.A., and Schneider, J.F., 1997, Model of strong ground motions from earthquakes in central and eastern North America: best estimates and uncertainties: Seism. Res. Lett., v. 68, no. 1, p. 41-57.

Wald, D.J., and Allen, T.I., 2007, Topographic slope as a proxy for seismic site conditions and amplification: Bull. Seism. Soc. Am., v. 97, no. 5, p. 1379-1395.

Wald, D.J., Earle, P.S., Lin, K., Quitoriano, V., and Worden, B.C., 2006a, Challenges in rapid ground motion estimation for the prompt assessment of global urban earthquakes: Bull. Earthq. Res. Inst., v. 81.

Wald, D.J., Lin, K., and Quitoriano, V., 2008, Quantifying and qualifying ShakeMap uncertainty: U.S. Geological Survey Open-File Report 2008-1238, 27 p.

Wald, D.J., Quitoriano, V., Dengler, L., and Dewey, J.W., 1999a, Utilization of the Internet for Rapid Community Intensity Maps: Seism. Res. Lett., v. 70, p. 680-697.

Wald, D.J., Quitoriano, V., and Dewey, J.W., 2006b, USGS "Did you feel it?" community internet intensity maps: macroseismic data collection via the internet, First European Conference on Earthquake Engineering and Seismology: Geneva, Switzerland, p. 10 pp.

Wald, D.J., Quitoriano, V., Heaton, T.H., and Kanamori, H., 1999b, Relationship between Peak Ground Acceleration, Peak Ground Velocity, and Modified Mercalli Intensity in California: Earthquake Spectra, v. 15, no. 3, p. 557-564.
Wald, D.J., Quitoriano, V., Heaton, T.H., Kanamori, H., Scrivner, C.W., and Worden, B.C., 1999c, TriNet "ShakeMaps": Rapid generation of peak ground-motion and intensity maps for earthquakes in southern California: Earthquake Spectra, v. 15, no. 3, p. 537-556.

Wald, D.J., Worden, B.C., Quitoriano, V., and Pankow, K.L., 2005, ShakeMap manual: technical manual, user's guide, and software guide: U.S. Geological Survey, 132 p.

Wells, D.L., and Coppersmith, K.J., 1994, New empirical relationships among magnitude, rupture length, rupture width, rupture area, and surface displacement: Bull. Seism. Soc. Am., v. 84, no. 4, p. 974-1002.

Wessel, P., and Smith, W.H.F., 1991, Generic Mapping Tools: EOS, v. 72, p. 441.

Wills, C.J., Petersen, M., Bryant, W.A., Reichle, M., Saucedo, G.J., Tan, S., Taylor, G., and Treiman, J., 2000, A site-conditions map for California based on geology and shear-wave velocity: Bull. Seism. Soc. Am., v. 90, no. 6B, p. S187-S208.

Youngs, R.R., Chiou, S.-J., Silva, W.J., and Humphrey, J.R., 1997, Strong ground motion attenuation relationships for subduction zone earthquakes: Seism. Res. Lett., v. 68, no. 1, p. $58-73$.

Zhang, P., Yang, Z.-X., Gupta, H.K., Bhatia, S.C., and Shedlock, K.M., 1999, Global seismic hazard assessment program (GSHAP) in continental Asia: Ann. Geofis., v. 42, no. 6, p. 1167-1190. 


\title{
Glossary
}

\author{
C
}

CERESIS Centro Regional de Sismología para

América

del Sur.

COSMOS Consortium of Organizations for Strong-Motion Observation Systems.

E

ESD European Strong-Motion Database

ETH Swiss Seismological Service, Swiss Federal Institute of Technology.

G

GMPE Ground Motion Prediction Equation.

GSM Global ShakeMap.

I

INGV Istituto Nazionale di Geofisica e Vulcanologia, Italy.

K

K-NET Kyoshin Network, Japan.

N

NGA Next Generation Attenuation.

NGDC National Geophysical Data

Center, National Oceanic and Atmospheric Administration (NOAA).

P

PAGER Prompt Assessment of Global Earthquakes for Response.

PGA Peak Ground Acceleration.

PGV Peak Ground Velocity. 


\section{Appendix I - List of Calibrated ShakeMaps}

List of calibrated ShakeMaps, including key sources of information (see Appendix_I.xls)

\section{Appendix II - References to Atlas Data Sources}

Abercrombie, R.E., Antolik, M., and Ekström, G., 2003, The June $2000 \mathrm{M}_{\mathrm{w}} 7.9$ earthquakes south of Sumatra: deformation in the India-Australia Plate: J. Geophys. Res., v. 108, no. B1, p. 2018.

Abercrombie, R.E., Antolik, M., Felzer, K.R., and Ekström, G., 2001, The 1994 Java tsunami earthquake: slip over a subducting seamount: J. Geophys. Res., v. 106, p. 6595-6608.

Acharya, H.K., 1978, Mindanao earthquake of August 16, 1976: preliminary seismological assessment: Bull. Seism. Soc. Am., v. 68, no. 5, p. 1459-1468.

Akamatsu, J., Morikawa, H., Nishimura, K., Onoue, K., Nakamura, M., Seto, N., Komazawa, M., Jiang, L., Li, K., and Luo, Q., 2000, Subsurface structure of Lijiang Basin, Yunnan, China, as related to damage distribution caused by the M7.0 Lijiang earthquake of February 3, 1996, in 12th World Conference on Earthquake Engineering, Auckland, New Zealand.

Allen, T.I., Cummins, P.R., Dhu, T., and Schneider, J.F., 2007, Attenuation of ground-motion spectral amplitudes in southeastern Australia: Bull. Seism. Soc. Am., v. 97, no. 4, p. 1279-1292.

Ambraseys, N.N., Lensen, G., Moinfar, A., and Pennington, W., 1981, The Pattan (Pakistan) earthquake of 28 December 1974: field observations: Q. J. eng. Geol. London, v. 14, p. $1-16$.

Amorèses, D., Grasso, J.-R., Plotnikova, L.M., Nurtaev, B.S., and Bossu, R., 1995, Rupture kinematics of the three Gazli major earthquakes from vertical and horizontal displacements data: Bull. Seism. Soc. Am., v. 85, no. 2, p. 552-559.

Anderson, H., Smith, E., and Robinson, R., 1990, Normal faulting in a back arc basin: Seismological characteristics of the March 2, 1987, Edgecumbe, New Zealand, earthquake: J. Geophys. Res., v. 95, no. B4, p. 4709-4723.

Anderson, J.G., Zeng, Y., and Sucuoglu, H., 2001, Analysis of accelerations from the 1 October 1995 Dinar, Turkey, earthquake: Bull. Seism. Soc. Am., v. 91, no. 6, p. 1433-1445.
Arioglu, E., and Anagol, K., 2002, Response of rural dwellings to recent destructive earthquakes in Turkey (1976-1977) and design criteria of earthquake resistan rural dwellings, $21 \mathrm{pp}$.

Asano, K., and Iwata, T., 2006, Source process and nearsource ground motions of the 2005 West Off Fukuoka Prefecture earthquake: Earth Planets Space, v. 58, no. 1, p. 93-98.

Astroza, M., 2007, Estudio de la zona afectada por el terremoto de Pisco: Agosto 15 del 2007: CERESIS/UNESCO, $21 \mathrm{p}$.

Ayadi, A., Ousadou-Ayadi, F., Bourouis, S., and Benhallou, H., 2002, Seismotectonics and seismic quietness of the Orani region (western Algeria): The Mascara earthquake of August 18th 1994, Mw=5.7, Ms=6.0: J. Seismol., v. 6, p. 13-23.

Badawy, A., and Monus, P., 1995, Dynamic source parameters of the 12th October 1992 earthquake, Cairo, Egypt: J. Geodyn., v. 20, no. 2, p. 99-109.

Barka, A., Akyuz, H.S., Altunel, E., Sunal, G., Cakir, Z., Dikbas, A., Yerli, B., Armijo, R., Meyer, B., de Chabalier, J.B., Rockwell, T., Dolan, J.R., Hartleb, R., Dawson, T., Christofferson, S., Tucker, A., Fumal, T., Langridge, R., Stenner, H., Lettis, W., Bachhuber, J., and Page, W., 2002, The surface rupture and slip distribution of the 17 August 1999 Izmit earthquake (M 7.4), north Anatolian fault: Bull. Seism. Soc. Am., v. 92, no. 1, p. 43-60.

Beck, S.L., and Ruff, L.J., 1989, Great earthquakes and subduction along the Peru trench: Phys. Earth Planet. Int., v. 57, p. 199-224.

Bendimerad, F., 2004, The 21 May 2003 Boumerdes earthquake lessons learned and recommendations, 13 WCEE: 13th World Conference on Earthquake Engineering Conference Proceedings: Vancouver, B.C., Canada.

Benetatos, C., and Kiratzi, A., 2006, Finite-fault slip models for the 15 April 1979 (Mw 7.1) Montenegro earthquake and its strongest aftershock of 24 May 1979 (Mw 6.2): Tectonophys., v. 421, p. 129-143.

Bennett, R.A., Reilinger, R.E., Rodi, W., Li, Y., and Toksoz, M.N., 1995, Coseismic fault slip associated with the 1992 Mw 6.1 Joshua Tree, California, earthquake: Implications for the Joshua Tree-Landers earthquake sequence: J. Geophys. Res., v. 100, no. B4, p. 6443-6461.

Berberian, M., 1979, Earthquake faulting and bedding thrust associated with the Tabas-e-Golshan (Iran) earthquake of September 16, 1978: Bull. Seism. Soc. Am., v. 69, no. 6, p. 1861-1887. 
Berberian, M., Asudeh, I., and Arshadi, S., 1979, Surface rupture and mechanism of the Bob-Tangol (southeastern Iran) earthquake of 19 December 1977: Earth Planet. Sci. Lett., v. 42 , p. $456-462$.

Berberian, M., Jackson, J.A., Fielding, E., Parsons, B.E., Priestley, K., Qorashi, M., Talebian, M., Walker, R., Wright, T.J., and Baker, C., 2001, The 1998 March 14 Fandoqa earthquake (Mw 6.6) in Kerman province, southeast Iran: re-rupture of the 1981 Sirch earthquake fault, triggeting of slip on adjacent thrusts and the active tectonics of the Gowk fault zone: Geophys. J. Int., v. 146, p. 371-398.

Berberian, M., and Papastamatiou, D., 1978, Khurgu (north Bandar Abbas, Iran) earthquake of March 21, 1977: a preliminary field report and a seismotectonic discussion: Bull. Seism. Soc. Am., v. 68, no. 2, p. 411-428.

Berberian, M., and Yeats, R.S., 1999, Patterns of historical earthquake rupture in the Iranian plateau: Bull. Seism. Soc. Am., v. 89, no. 1, p. 120-139.

Bernard, P., Briole, P., Meyer, B., Lyon-Caen, H., Gomez, J.-M., Tiberi, C., Berge, C., Cattin, R., Hatzfeld, D., Lachet, C., Lebrun, B., Deschamps, A., Courboulex, F., Larroque, C., Rigo, A., Massonnet, D., Papadimitriou, P., Kassaras, J., Diagourtas, D., Makropoulos, K., Veis, G., Papazisi, E., Mitsakaki, C., Karakostas, V., Papadimitriou, E., Papanastassiou, D., Chouliaras, M., and Stavrakakis, G., 1997a, The MS=6.2, June 15, 1995 Aigion earthquake (Greece): evidence for low angle normal faulting in the Corinth rift: $\mathrm{J}$. Seismol., v. 1, no. 131-150.

Bernard, P., Gariel, J.-C., and Dorbath, L., 1997b, Fault location and rupture kinematics of the magnitude 6.8, 1992 Erzincan earthquake, Turkey, from strong ground motion and regional records: Bull. Seism. Soc. Am., v. 87, no. 5, p. 1230-1243.

Beroza, G.C., and Spudich, P., 1988, Linearized inversion for fault rupture behavior; application to the 1984 Morgan Hill, California, earthquake: J. Geophys. Res., v. 93, no. B6, p. 6275-6296.

Boore, D.M., Sims, J.D., Kanamori, H., and Harding, S., 1981, The Montenegro, Yugoslavia, earthquake of April 15, 1979: source orientation and strength: Phys. Earth Planet. Int., v. 27, p. 133-142.

Bourgeois, J., Petroff, C., Yeh, H., Titov, V., Synolakis, C.E., Benson, B., Kuroiwa, J., Lander, J., and Norabuena, E., 1999, Geolgic setting, field survey and modeling of the Chimbote, Northern Peru, Tsunami of 21 February 1996: Pure Appl. Geophys., v. 154, p. 513-540.

Cajka, M., and Drysdale, J., 1996, Intensity report of the November 25, 1988 Saguenay, Québec, earthquake: Geological Survey of Canada, Open File Report 3279.
Castro, R.R., and Ruíz-Cruz, E., 2005, Stochastic modeling of the 30 September 1999 Mw 7.5 earthquake, Oaxaca, Mexico: Bull. Seism. Soc. Am., v. 95, no. 6, p. 2259-2271.

Chen, Y.T., Xu, L.S., Li, X., and Zhao, M., 1996, Source process of the 1990 Gonghe, China, earthquake and tectonic stress field in the northeastern Qinghai-Xizang (Tibetan) plateau: Pure Appl. Geophys., v. 146, no. 3/4, p. 695-715.

Choy, G.L., and Zednik, J., 1997, The rupture process of the Manjil, Iran earthquake of 20 June 1990 and implications for intraplate strike-slip earthquakes: Studiageoph. etgeod., v. 41, p. $45-63$.

Courboulex, F., Santoyo, M.A., Pacheco, J.F., and Singh, S.K., 1997, The 14 September 1995 ( $M=7.3$ ) Copala, Mexico, earthquake: a source study using teleseismic, regional, and local data: Bull. Seism. Soc. Am., v. 87, no. 4, p. 999-1010.

Crosson, R.S., Martini, M., Scarpa, R., and Key, S.C., 1986, The southern Italy earthquake of 23 November 1980: an unusual pattern of faulting: Bull. Seism. Soc. Am., v. 76, no. 2, p. 381-394.

Delouis, B., Monfret, T., Dorbath, L., Pardo, M., Rivera, L., Comte, D., Haessler, H., Caminade, J.P., Ponce, L., Kausel, E., and Cisternas, A., 1997, The Mw = 8.0 Antofagasta (Northern Chile) earthquake of 30 July 1995: a precursor to the end of the large 1877 gap: Bull. Seism. Soc. Am., v. 87, no. 2, p. 427-445.

Deschamps, A., Gaudemer, Y., and Cisternas, A., 1982, The El Asnam, Algeria, earthquake of 10 October 1980: multiplesource mechanism determined from long-period records: Bull. Seism. Soc. Am., v. 72, no. 4, p. 1111-1128.

Dewey, J.W., and Spence, W., 1979, Seismic gaps and source zones of recent large earthquakes in costal Peru: Pure Appl. Geophys., v. 117, p. 1148-1171.

Dhu, T., and Jones, T., 2002, Earthquake risk in Newcastle and Lake Macquarie: Geoscience Australia Record 2002/15, Canberra.

Disaster Control Research Center, May 26, 2003 MiyagiOki (Japan) earthquake, Graduate School of Engineering, Tohoku University, http://www.disaster.archi.tohoku.ac.jp/ eng/topicse/030526htm/030526e.htm, accessed March 2008 .

Espinosa, A.F., Hall, M.L., and Yepes, H., 1991, The March 5, 1987, Ecuador Earthquake: Mass Wasting and Socioeconomic Effects - Tectonics and Seismicity, National Acadamies Press, v. 5, p. 29-41.

Eyidogan, H., Nalbant, S.S., Barka, A., and King, G.C.P., 1999, Static stress changes induced by the 1924 Pasinler $(\mathrm{M}=6.8)$ and 1983 Horasan-Narma $(\mathrm{M}=6.8)$ earthquakes, Northeastern Turkey: Terra Nova, v. 11, no. 1, p. 38-44. 
Farahbod, A.M., Lindholm, C., Mokhtari, M., and Bungum, H., 2003, Aftershock analysis for the 1997 Ghaen-Birjand (Ardekul) earthquake: Journal of Seismology and Earthquake Engineering, v. 5, no. 2, p. 1-10.

Fenton, C.H., and Bommer, J.J., 2006, The $\mathrm{M}_{\mathrm{w}} 7$ Machaze, Mozambique, earthquake of 23 February 2006: Seism. Res. Lett., v. 77, no. 4, p. 426-439.

Fuenzalida, H., Rivera, L., Haessler, H., Legrand, D., Philip, H., Dorbath, L., McCormack, D., Arefiev, S., Langer, C., and Cisternas, A., 1997, Seismic source study of the RachaDzhava (Georgia) earthquake from aftershocks and broadband teleseismic body-wave records: an example of active nappe tectonics: Geophys. J. Int., v. 130, p. 29-46.

Fukuyama, E., and Irikura, K., 1986, Rupture process of the 1983 Japan Sea (Akita-Oki) earthquake using a waveform inversion method: Bull. Seism. Soc. Am., v. 76, no. 6, p. $1623-1640$.

Funning, G.J., Parsons, B., Wright, T.J., Jackson, J.A., and Fielding, E.J., 2005, Surface displacements and source parameters of the 2003 Bam (Iran) earthquake from Envisat advanced synthetic aperture radar imagery: J. Geophys.

Res., v. 110, no. B09406, p. 1-23.

Gettrust, J.F., Hsu, V., Helsley, C.E., Herrero, E., and Jordan, T., 1981, Patterns of local seismicity preceding the Petatlan earthquake of 14 March 1979: Bull. Seism. Soc. Am., v. 71, no. 3, p. 761-769.

Ghose, S., Mellors, R.J., Korjenkov, A.M., Hamburger, M.W., Pavlis, T.L., Pavlis, G.L., Omuraliev, M., Mamyrov, E., and Muraliev, A.R., 1997, The Ms = 7.31992 Suusamyr, Kyrgyzstan, earthquake in the Tien Shan: 2. aftershock focal mechanisms and surface deformation: Bull. Seism. Soc. Am., v. 87, no. 1, p. 23-38.

Giovanni, M.K., Beck, S.L., and Wagner, L., 2002, The June 23, 2001 Peru earthquake and the southern Peru subduction zone: Geophys. Res. Lett., v. 29, no. 21, p. 2018-2021.

Gomez, J.M., Madariaga, R., Walpersdorf, A., and Chalard, E., 2000, The 1996 earthquakes in Sulawesi, Indonesia: Bull. Seism. Soc. Am., v. 90, no. 3, p. 739-751.

Gonzalez, J., Schmitz, M., Audemard, F., Contreras, R., Mocquet, A., Delgado, J., and De Santis, F., 2004, Site effects of the 1997 Cariaco, Venezuela earthquake: Eng. Geol., v. 72, p. 143-177.

Gupta, H.K., and Combs, J., 1978, Investigation of isoseismals for some large magnitude earthquakes in China: Bull. Seism. Soc. Am., v. 68, no. 1, p. 193-204.

Gupta, H.K., Rastogi, B.K., Mohan, I., Rao, C.V.R.K., Sarma, S.V.S., and Rao, R.U.M., 1998, An investigation into the Latur earthquake of September 29, 1993 in southern India: Tectonophys., v. 287, p. 299-318.
Haghipour, A., and Amidi, M., 1980, The November 14 to December 25, 1979 Ghaenat earthquakes of northeast Iran and their tectonic implications: Bull. Seism. Soc. Am., v. 70 , no. 5, p. 1751-1757.

Hahou, Y., Jabour, N., Oukemeni, D., El Wartiti, M., and Nakhcha, C., 2002, The earthquake of May 26, 1994, Al Hoceima, Morocco; intensity distribution and macroseismic epicenter, in Second Annual IIASA-DPRI Meeting, Laxenburg, Austria.

Harbi, A., Maouche, S., Ousadou, F., Rouchiche, Y., YellesChaouche, A., Merahi, M., Heddar, A., Nouar, O., Kherroubi, A., Beldjoudi, H., Ayadi, A., and Benouar, D., 2007, Macroseismic study of the Zemmouri earthquake of 21 May 2003 (Mw 6.8, Algeria): Earthq. Spectra, v. 23, no. 2, p. 315-332.

Harlow, D.H., White, R.A., Rymer, M.J., and Alvarez G, S., 1993, The San Salvador earthquake of 10 October 1986 and its historical context: Bull. Seism. Soc. Am., v. 83, no. 4, p. 1143-1154.

Hartzell, S., 1989, Comparison of waveform inversion results for the rupture history of finite fault: application to the 1986 North Palm Springs, California, earthquake: J. Geophys. Res., v. 94, no. B6, p. 7515-7534.

Hartzell, S., Langer, C., and Mendoza, C., 1994, Rupture histories of eastern North American earthquakes: Bull. Seism. Soc. Am., v. 84, no. 6, p. 1703-1724.

Hartzell, S., and Mendoza, C., 1991, Application of an iterative least-squares waveform inversion of strong-motion and teleseismic records to the 1978 Tabas, Iran, earthquake: Bull. Seism. Soc. Am., v. 81, no. 2, p. 305-331.

He, H., Oguchi, T., Zhou, R., Zhang, J., and Qiao, S., 2001, Damage and seismic intensity of the 1996 Lijiang earthquake, China: A GIS analysis, CSIS Discussion Paper \#36, Center for Spatial Information Science, The University of Tokyo, $19 \mathrm{p}$.

Henry, C., and Das, S., 2002, The Mw 8.2, 17 February 1996 Biak, Indonesia earthquake: rupture history, aftershocks, and fault plane properties: J. Geophys. Res., v. 107, no. B11.

Hernandez, B., Cocco, M., Cotton, F., Stramondo, S., Scotti, O., Courboulex, F., and Campillo, M., 2004, Rupture history of the 1997 Umbria-Marche (central Italy) main shocks from the inversion of GPS, DInSAR and near field strong motion data: Ann. Geophys.-Italy, v. 47, no. 4, p. 1355-1376.

Hikima, K., and Koketsu, K., 2004, Source processes of the foreshock, mainshock and largest aftershock in the 2003 Miyagi-ken Hokubu, Japan, earthquake sequence: Earth Planets Space, v. 56, p. 87-93. 
Hollingsworth, J., Jackson, J., Alarcón, Bommer, J.J., and Bolourchi, M.J., 2007, The 4th February 1997 Bojnurd (Garmkhan) earthquake in NE Iran: field, teleseismic, and strong-motion evidence for rupture directivity effects on a strike-slip fault: J. Earthq. Eng., v. 11, p. 193-214.

Horikawa, H., 2001, Earthquake doublet in Kagoshima, Japan: rupture of asperities in a stress shadow: Bull. Seism. Soc. Am., v. 91, no. 1, p. 112-127.

Huang, B.-S., and Yeh, Y.T., 1997, The fault ruptures of the 1976 Tangshan earthquake sequence inferred from coseismic crustal deformation: Bull. Seism. Soc. Am., v. 87, no. 4, p. 1046-1057.

Hurtado, E.J.S., and Capera, A.G., 2000, Atlas macrosísmico de Colombia: Sismotectónica del Territorio, Colombiano, $108 \mathrm{p}$.

Hwang, L.J., and Kanamori, H., 1989, Telesiesmic and strongmotion source spectra from two earthquakes in eastern Taiwan: Bull. Seism. Soc. Am., v. 79, no. 4, p. 935-944.

Ide, S., 1999, Source process of the 1997 Yamaguchi, Japan, earthquake analyzed in different frequency bands: Geophys. Res. Lett., v. 26, no. 13, p. 1973-1976.

Ivashchenko, A.I., Kim, C.U., Oscorbin, L.S., Poplavskaya, L.N., Poplavsky, A.A., Burymskaya, R.N., Mikhailova, T.G., Vasilenko, N.F., and Streltsov, M.I., 1997, The Neftegorsk, Sakhalin Island, earthquake of 27 May 1995: Isl. Arc, v. 6, p. 288-302.

Ji, C., 2004, Slip history the 2004 (Mw 5.9) Parkfield earthquake (single-plane model): Pasadena, Caltech, v. 2008, no. March 26.

Ji, C., Helmberger, D.V., Wald, D.J., and Ma, K.-F., 2003, Slip history and dynamic implications of the 1999 Chi-Chi, Taiwan, earthquake: J. Geophys. Res., v. 108, no. B9, p. 2412.

Jonsson, S., Zebker, H., Segall, P., and Amelung, F., 2002, Fault slip distribution of the 1999 Mw 7.1 Hector Mine, California, earthquake, estimated from satellite radar and GPS measurements: Bull. Seism. Soc. Am., v. 92, no. 4, p. 1377-1389.

Joshi, A., and Mohan, K., 2008, Simulation of accelerograms from simplified deterministic approach for the 23rd October 2004 Niigata-ken Chuetsu, Japan earthquake: J. Seismol., v. 12 , p. $35-51$.

Katsumata, K., Kasahara, M., Ichiyanagi, M., Kikuchi, M., Sen, R.-S., Kim, C.-U., Ivaschenko, A., and Tatevossian, R., 2004, The 27 May 1995 Ms 7.6 northern Sakhalin earthquake: an earthquake on an uncertain plate boundary: Bull. Seism. Soc. Am., v. 94, no. 1, p. 117-130.
Koketsu, D., Hikima, K., Miyazaki, S., and Ide, S., 2004, Joint inversion of strong motion and geodetic data for the source process of the 2003 Tokachi-oki, Hokkaido, earthquake: Earth Planets Space, v. 56, no. 3, p. 329-334.

Konstantinou, K.I., Kalogeras, I.S., Melis, N.S., Kourouzidis, M.C., and Stavrakakis, G.N., 2006, The 8 January 2006 earthquake $\left(M_{W} 6.7\right)$ offshore Kythira Island, southern Greece: seismological, strong-motion, and macroseismic observations of an intermediate-depth event: Seism. Res. Lett., v. 77, no. 5, p. 544-553.

Langer, C.J., Bonilla, M.G., and Bollinger, G.A., 1987, Aftershocks and surface faulting associated with the intraplate Guinea, west Africa, earthquake of 22 December 1983: Bull. Seism. Soc. Am., v. 77, no. 5, p. 1579-1601.

Langer, C.J., and Hartzell, S., 1996, Rupture distribution of the 1977 western Argentina earthquake: Phys. Earth Planet. Int., v. 94 , p. $121-132$.

Larsen, S., Reilinger, R., Neugebauer, H., and Strange, W., 1992, Global positioning system measurements of deformations associated with the 1987 Superstition Hills earthquake-evidence for conjugate faulting: J. Geophys. Res., v. 97, no. B4, p. 4885-4902.

Lewis, J.D., Daetwyler, N.A., Bunting, J.A., and Moncrieff, J.S., 1981, The Cadoux earthquake: Western Australia Geological Survey Report, 1981/11, 133 p.

Lin, A., Kikuchi, M., and Fu, B., 2003, Rupture segmentation and process of the $2001 \mathrm{M}_{\mathrm{w}} 7.8$ central Kunlun, China, earthquake: Bull. Seism. Soc. Am., v. 93, no. 6, p. 2477-2492.

Lomnitz, C., and Hashizume, M., 1985, The Popayán, Colombia, earthquake of 31 March 1983: Bull. Seism. Soc. Am., v. 75 , no. 5 , p. $1315-1326$.

Mahajan, A.K., Kumar, S., and Kamal, 2004, Macroseismic field observations of January 26th, 200 Kachchh earthquake and its seismotectonics: J. Asian Earth Sci., v. 23, p. 17-23.

Mahajan, A.K., and Virdi, N.S., 2001, Macroseismic field generated by 29 March, 1999 Chamoli earthquake and its seismotectonics: J. Asian Earth Sci., v. 19, p. 507-516.

Mandal, P., Rastogi, B.K., and Gupta, H.K., 2000, Recent Indian earthquakes: Current Science, v. 79, no. 9, p. 1334-1346.

Matias, L., Dias, N.A., Morais, I., D., V., Carrilho, F., Madeira, J., Gaspar, J.L., Senos, L., and Silveira, A.B., 2007, The 9th of July 1998 Faial Island (Azores, North Atlantic) seismic sequence: J. Seismol., v. 11, p. 275-298.

Meidow, H., and Ahorner, L., 1994, Macroseismic effects in Germany of the 1992 Roermond earthquake and their interpretation: Geol. Mijnbouw, v. 73, p. 271-279. 
Mellors, R.J., Vernon, F.L., Pavlis, G.L., Abers, G.A., Hamburger, M.W., Ghose, S., and Iliasov, B., 1997, The $\mathrm{M}_{\mathrm{S}}=$ 7.31992 Suusamyr, Kyrgyzstan, earthquake: constraints on fault geometry and source parameters based on aftershocks and body-wave modeling: Bull. Seism. Soc. Am., v. 87, no. 1 , p. 11-22.

Mendoza, C., 1993, Coseismic slip of two large Mexican earthquakes from teleseismic body wave-formsimplications for asperity interaction in the Michoacan Plate boundary segment: J. Geophys. Res., v. 98, no. B5, p. 8197-8210.

Mendoza, C., 1995, Finite-fault analysis of the 1979 March 14 Petatlan, Mexico, earthquake using teleseismic P-waveforms: Geophys. J. Int., v. 121, no. 3, p. 675-683.

Mendoza, C., and Dewey, J.W., 1984, Seismicity associated with the great Colombia-Ecuador earthquakes of 1942 , 1958, and 1979: implications for barrier models of earthquake ruptures: Bull. Seism. Soc. Am., v. 74, no. 2, p. 577-593.

Mendoza, C., and Fukuyama, E., 1996, The July 12, 1993, Hokkaido-Nansei-Oki, Japan, earthquake: coseismic slip pattern from strong-motion and teleseismic recordings: J. Geophys. Res., v. 101, no. B1, p. 791-802.

Mendoza, C., and Hartzell, S., 1988, Inversion for slip distribution using teleseismic P waveforms; North Palm Springs, Borah Peak, and Michoacan earthquakes: Bull. Seism. Soc. Am., v. 78, no. 3, p. 1092-1111.

Mendoza, C., and Hartzell, S., 1999, Fault-slip distribution of the 1995 Colima-Jalisco, Mexico, earthquake: Bull. Seism. Soc. Am., v. 89, p. 1338-1344.

Mendoza, C., Hartzell, S., and Monfret, T., 1994, Wide-band analysis of the 3 March 1985 central Chile earthquake: overall source process and rupture history: Bull. Seism. Soc. Am., v. 84, no. 2, p. 269-283.

Mendoza, C., and Hartzell, S.H., 1989, Slip distribution of the 19 September 1985 Michoacan, Mexico, earthquake - nearsource and teleseismic constraints: Bull. Seism. Soc. Am., v. 79 , no. 3 , p. 655-669.

Mozaffari, P., Wu, Z.-L., and Chen, Y.-T., 1998, Rupture process of November 6, 1988, Lancang-Gengma, Yunnan, China, earthquake of $\mathrm{M}_{\mathrm{s}}=7.6$ using empirical Green's function deconvolution method: Acta Seismologica Sinica, v. 11, no. 1 , p. 1-12.

Nakahara, H., Nishimura, T., Sato, H., Ohtake, M., Kinoshita, S., and Hamaguchi, H., 2002, Broadband source process of the 1998 Iwate prefecture, Japan, earthquake as revealed from inversion analyses of seismic waveforms and envelopes: Bull. Seism. Soc. Am., v. 92, no. 5, p. 1708-1720.
Nakayama, W., and Takeo, M., 1997, Slip history of the 1994 Sanriku-Haruka-Oki, Japan, earthquake deduced from strong-motion data: Bull. Seismol. Soc. Am., v. 87, no. 4, p. 918-931.

Nalbant, S.S., McCloskey, J., and Steacy, S., 2005, Lessons on the calculation of static stress loading from the 2003 Bingol, Turkey earthquake: Earth Planet. Sci. Lett., v. 235, p. $632-640$.

National Geophysical Data Center, 2008, Earthquake intensity database: Boulder, National Oceanic and Atmospheric Administration, v. 2008, no. March 26.

Nava, F.A., Toledo, V.R., and Lomnitz, C., 1985, Plate waves and the 1980 Huajuapan de Leon, Mexico earthquake: Tectonophys., v. 112, p. 463-492.

Oglesby, D.D., Dreger, D.S., Harris, R.A., Ratchkovski, N., and Hansen, R., 2004, Inverse kinematic and forward dynamic models of the 2002 Denali fault earthquake, Alaska: Bull. Seism. Soc. Am., v. 94, no. 6, p. S214-S233.

Ohtake, M., 1976, Search for precursors of the 1974 IzuHanto-oki earthquake, Japan: Pure Appl. Geophys., v. 114, p. 1083-1093.

Papadimitriou, E., Wen, X., Karakostas, V., and Jin, X., 2004, Earthquake triggering along the Xianshuihe Fault Zone of western Sichuan, China: Pure Appl. Geophys., v. 161, p. 1683-1707.

Papadopoulos, G.A., Matsumoto, H., Ganas, A., Karastathis, V., and Pavlides, S., 2004, Deformation patterns associated with the M5.9 Athens (Greece) earthquake of 7 September 1999: J. Seismol, v. 8, p. 381-394.

Park, S.-C., and Mori, J., 2008, The 2004 sequence of triggered earthquakes off the Kii peninsula, Japan: Earth Planets Space, v. 57, p. 315-320.

Parsons, T., Barka, A., Toda, S., Stein, R.S., and Dieterich, J.H., 2000, Influence of the 17 August 1999 Izmit earthquake on seismic hazards in Istanbul, in Barka, A., Kozaci, O., S., A., and Altunel, E., eds., The 1999 Izmit and Duzce Earthquakes: Preliminary results: Istanbul, Istanbul Tech. Univ. Press, p. 295-310.

Pérez, O.J., 1998, Seismological report on the $\mathrm{M}_{\mathrm{w}}=6.8$ strong shock of 9 July 1997 in Cariaco, northeastern Venezuela: Bull. Seism. Soc. Am., v. 88, no. 3, p. 874-879.

Plafker, G., Agar, R., Asker, A.H., and Hanif, M., 1987, Surface effects and tectonic setting of the 13 December 1982 north Yemen earthquake: Bull. Seism. Soc. Am., v. 77, no. 6, p. 2018-2037. 
Protti, M., McNally, K., Pacheco, J., Gonzalez, V., Montero, C., Segura, J., Brenes, J., Barboza, V., Malavassi, E., Güendel, F., Simila, G., Rojas, D., Velasco, A., Mata, A., and Schillinger, W., 1995, The March 25, $1990\left(\mathrm{M}_{\mathrm{w}}=7.0\right.$, $M_{L}=6.8$ ), earthquake at the entrance of the Nicoya Gulf, Costa Rica: Its prior activity, foreshocks, aftershocks, and triggered seismicity: J. Geophys. Res., v. 100, no. B10, p. $20,345-20,358$.

Radu, C., Polonic, G., and Apopei, I., 1979, Macroseismic field of the March 4, 1977 Vrancea earthquake: Tectonophys., v. 53, p. 185-186.

Radulian, M., and Popa, M., 1996, Scaling of source parameters for Vrancea (Romania) intermediate depth earthquakes: Tectonophys., v. 261, p. 37-81.

Rajendran, C.P., Rajendran, K., and John, B., 1996, The 1993 Killari (Latur), central India, earthquake: An example of fault reactivation in the Precambrian crust: Geol., v. 24, no. 7, p. 651-654.

Reyes, A., Brune, J.N., and Lomnitz, C., 1979, Source mechanism and aftershock study of the Colima, Mexico earthquake of January 30, 1973: Bull. Seism. Soc. Am., v. 69, no. 6 , p. 1819-1840.

Roumelioti, Z., and Kiratzi, A., 2002, Stochastic simulation of strong-motion records from the 15 April 1979 (M 7.1) Montenegro earthquake: Bull. Seism. Soc. Am., v. 92, no. 3, p. 1095-1101.

Roumelioti, Z., Kiratzi, A., and Theodulidis, N., 2004, Stochastic strong ground-motion simulation of the 7 September 1999 Athens (Greece) earthquake: Bull. Seism. Soc. Am., v. 94 , no. 3 , p. 1036-1052.

Salichon, J., Delouis, B., Lundgren, P., Giardini, D., Costantini, M., and Rosen, P., 2003, Joint inversion of broadband teleseismic and interferometric synthetic aperture radar (InSAR) data for the slip history of the Mw=7.7, Nazca ridge (Peru) earthquake of 12 November 1996: J. Geophys. Res., v. 108, no. B2, p. 2085.

Satake, K., 1995, Linear and nonlinear computations of the 1992 Nicaragua earthquake tsunami: Pure Appl. Geophys., v. 144 , no. $3 / 4$, p. $455-470$.

Satyabala, S.P., and Bilham, R., 2006, Surface deformation and subsurface slip of the 28 March $1999 \mathrm{Mw}=6.4$ west Himalayan Chamoli earthquake from InSAR analysis: Geophys. Res. Lett., v. 33, no. L23305, p. 1-5.

Schenková, Z., Schenk, V., Kalogeras, I., Pichl, R., Kottnauer, P., Papatsimba, C., and Panopoulou, G., 2007, Isoseismal maps drawing by the kriging method: J. Seismol., v. 11, p. 121-129.
Schwartz, S.Y., 1995, Source parameters of aftershocks of the 1991 Costa Rica and 1992 Cape Mendocino, California, earthquakes from inversion of local amplitude ratios and broadband waveforms: Bull. Seism. Soc. Am., v. 85, no. 6, p. $1560-1575$.

Semmane, F., Cotton, F., and Campillo, M., 2005, The 2000 Tottori earthquake: A shallow earthquake with no surface rupture and slip properties controlled by depth: J. Geophys. Res., v. 110, no. B3, p. 306.

Shimazaki, K., 1974, Nemuro-Oki earthquake of June 17, 1973: a lithospheric rebound at the upper half of the interface: Phys. Earth Planet. Int., v. 9, p. 314-327.

Shimazaki, K., and Somerville, P., 1979, Static and dynamic parameters of the Izu-Oshima, Japan earthquake of January 14, 1978: Bull. Seism. Soc. Am., v. 69, no. 5, p. 1343-1137.

Shoja-Taheri, J., and Anderson, J.G., 1988, The 1978 Tabas, Iran, earthquake: an interpretation of the strong motion records: Bull. Seism. Soc. Am., v. 78, no. 1, p. 142-171.

Shoja-Taheri, J., Naserieh, S., and Ghafoorian-Nasab, A.H., 2005, The 2003 Bam, Iran, earthquake: an interpretation of the strong motion records: Earthq. Spectra, v. 21, no.S1, p. S181-S206.

Singh, S.K., Bansal, B.K., Bhattacharya, S.N., Pacheco, J.F., Dattatrayam, R.S., Ordaz, M., Suresh, G., Kamal, and Hough, S.E., 2003, Estimation of ground motion for Bhuj (26 January 2001; $M_{\mathrm{w}}$ 7.6) and for future earthquakes in India: Bull. Seism. Soc. Am., v. 93, no. 1, p. 353-370.

Singh, S.K., Havskov, J., McNally, K., Ponce, L., Hearn, T., and Vassiliou, M., 1980, The Oaxaca, Mexico, earthquake of 29 November 1978: a preliminary report on aftershocks: Science, v. 207, no. 4436, p. 1211-1213.

Singh, S.K., Ordaz, M., and Pérez-Rocha, L.E., 1996, The great Mexican earthquake of 19 June 1858: expected ground motions and damage in Mexico City from a similar future event: Bull. Seism. Soc. Am., v. 86, no. 6, p. 1655-1666.

Smith, K.D., and Priestley, K.F., 2000, Faulting in the 1986 Chalfant, California, sequence: local tectonics and earthquake source parameters: Bull. Seism. Soc. Am., v. 90, no. 4 , p. 813-831.

Sokolov, V.Y., 2002, Seismic intensity and Fourier acceleration spectra: revised relationship: Earthq. Spectra, v. 18, no. 1, p. $161-187$.

Spence, W., Mendoza, C., Engdahl, E.R., Choy, G.L., and Norabuena, E., 1999, Seismic subduction of the Nazca Ridge as shown by the 1996-97 Peru earthquakes: Pure Appl. Geophys., v. 154, p. 753-776. 
Stich, D., Mancilla, F.L., Baumont, D., and Morales, J., 2005, Source analysis of the $M_{w} 6.32004 \mathrm{Al}$ Hoceima earthquake (Morocco) using regional apparent source time functions: J. Geophys. Res., v. 110, no. B06306, p. doi:10.1029/2004JB003366.

Tajima, F., 1984, Study of the source processes of the 1965, 1968 and 1978 Oaxaca earthquakes using short-period records: J. Geophys. Res., v. 89, no. B3, p. 1867-1873.

Takeo, M., 1988, Rupture process of the 1980 Izu-HantoToho-Oki earthquake deduced from strong motion seismograms: Bull. Seism. Soc. Am., v. 78, no. 3, p. 1074-1091.

Takeo, M., and Mikami, N., 1987, Inversion of strong motion seismograms for the source process of the Naganoken-Seibu earthquake of 1984: Tectonophys., v. 144, no. 1-3, p. 271-285.

Talebian, M., Biggs, J., Bolourchi, M., Copley, A., Ghassemi, A., Ghorashi, M., Hollingsworth, J., Jackson, J., Nissen, E., Oveisi, B., Parsons, B., Priestley, K., and Saiidi, A., 2006, The Dahuiyeh (Zarand) earthquake of 2005 February 22 in central Iran: reactivation of an intramountain reverse fault: Geophys. J. Int., v. 164, p. 137-148.

Tanioka, Y., Satake, K., and Ruff, L., 1995, Analysis of seismological and tsunami data from the 1993 Guam earthquake: Pure Appl. Geophys., v. 144, no. 3/4, p. 823-837.

Tavera, H., and Bernal, I., in press, The Pisco (Peru) earthquake of August 15th, 2007: Seism. Res. Lett., v. 79, no. 4.

Tavera, H., Buforn, E., Bernal, I., Antayhua, Y., and Vilacapoma, L., 2002, The Arequipa (Peru) earthquake of June 23, 2001: J. Seismol., v. 6, p. 279-283.

Teves-Costa, P., Oliveirab, C.S., and Senos, M.L., 2007, Effects of local site and building parameters on damage distribution in Angra do Heroísmo-Azores: Soil Dyn. Earthq. Eng., v. 27, p. 986-999.

Tilford, N.R., Chandra, U., Amick, D.C., Moran, R., and Snider, F., 1985, Attenuation of intensities and effect of local site conditions on observed intensities during the Corinth, Greece earthquakes of 24 and 25 February and 4 March 1981: Bull. Seism. Soc. Am., v. 75, no. 4, p. 923-937.

Tranosa, M.D., Papadimitriou, E.E., and Kilias, A.A., 2003, Thessaloniki-Gerakarou Fault Zone (TGFZ): the western extension of the 1978 Thessaloniki earthquake fault (Northern Greece) and seismic hazard assessment: J. Struct. Geol., v. 25 , p. 2109-2123.

Tselentis, G.-A., and Zahradnik, J., 2000, The Athens earthquake of 7 September 1999: Bull. Seism. Soc. Am., v. 90, no. 5, p. 1143-1160.
Tsuji, Y., Imamura, F., Matsutomi, H., Synolakis, C.E., Nanang, R.T., Jumadi, Harada, S., Han, S.S., Arai, K., and Cook, B., 1995, Field survey of the east Java earthquake and tsunami of June 3, 1994: Pure Appl. Geophys., v. 144, no. $3 / 4$, p. $839-854$.

Ueda, H., Ohtake, M., and Sato, H., 2001, Afterslip of the plate interface following the 1978 Miyagi-Oki, Japan earthquake, as revealed from geodetic measurement data: Tectonophys., v. 338, p. 45-57.

Ulusay, R., and Kuru, T., 2004, 1998 Adana-Ceyhan (Turkey) earthquake and a preliminary microzonation based on liquefaction potential for Ceyhan town: Nat. Hazards, v. 32, p. 59-88.

Vallée, M., and Bouchon, M., 2003, The 13 January 2001 El Salvador earthquake: a multidata analysis: J. Geophys. Res., v. 108, no. B4, p. 2203.

Wald, D.J., 1992, Strong motion and broad band teleseismic analysis of the 1991 Sierra-Madre, California, earthquake: J. Geophys. Res., v. 97, no. B7, p. 11033-11046.

Wald, D.J., 1996, Slip history of the 1995 Kobe, Japan, earthquake determined from strong motion, teleseismic, and geodetic data: J. Phys. Earth, v. 44, no. 5, p. 489-503.

Wald, D.J., and Heaton, T.H., 1994, Spatial and temporal distribution of slip for the 1992 Landers, California, earthquake: Bull. Seism. Soc. Am., v. 84, no. 3, p. 668-691.

Wald, D.J., Heaton, T.H., and Hudnut, K.W., 1996, The slip history of the 1994 Northridge, California, earthquake determined from strong-motion, teleseismic, GPS, and leveling data: Bull. Seism. Soc. Am., v. 86, no. 1B, p. S49-S70.

Wald, D.J., Helmberger, D.V., and Hartzell, S.H., 1990, Rupture process of the 1987 Superstition Hills earthquake from the inversion of strong-motion data: Bull. Seism. Soc. Am., v. 80 , no. 5 , p. 1079-1098.

Wald, D.J., Helmberger, D.V., and Heaton, T.H., 1991, Rupture model of the 1989 Loma Prieta earthquake from the inversion of strong-motion and broadband teleseismic data: Bull. Seism. Soc. Am., v. 81, no. 5, p. 1540-1572.

Walker, R.T., Bergman, E., Jackson, J., Ghorashi, M., and Talebian, M., 2005, The 2002 June 22 Changureh (Avaj) earthquake in Qazvin province, northwest Iran: epicentral relocation, source parameters, surface deformation and geomorphology: Geophys. J. Int., v. 160, p. 707-720.

Wang, K., Chen, Q.-F., Sun, S., and Wang, A., 2006, Predicting the 1975 Haicheng earthquake: Bull. Seism. Soc. Am., v. 96 , no. 3 , p. $757-795$. 
Yagi, Y., Kikuchi, M., Yoshida, S., and Sagiya, T., 1999, Comparison of the coseismic rupture with the aftershock distribution in the Hyuga-nada earthquakes of 1996: Geophys. Res. Lett., v. 26, no. 20, p. 3161-3164.

Yagi, Y., Mikumo, T., Pacheco, J., and Reyes, G., 2004, Source rupture process of the Tecoman, Colima, Mexico, earthquake of 22 January 2003, determined by joint inversion of teleseismic body-wave and near-source data: Bull. Seism. Soc. Am., v. 94, no. 5, p. 1795-1807.

Yalcinkaya, E., 2005, Stochastic finite-fault modeling of ground motions from the June 27, 1998 Adana-Ceyhan earthquake: Earth Planets Space, v. 57, p. 107-115.

Yamada, M., Park, S.-C., and Mori, J., 2008, The 2007 Noto Peninsula, Japan, earthquake $\left(M_{w} 6.7\right)$ : damage to wooden structures: Seism. Res. Lett., v. 79, no. 1, p. 20-24.

Yamamoto, J., Quintanar, L., Rebollar, C.J., and Jiménez, Z., 2002, Source characteristics and propagation effects of the Puebla, Mexico, earthquake of 15 June 1999: Bull. Seism. Soc. Am., v. 92, no. 6, p. 2126-2138.

Yeats, R.S., and Madden, C., 2003, Damage from the Nahrin, Afghanistan, earthquake of 25 March 2002: Seism. Res. Lett., v. 74, no. 3, p. 305-311.

Zeng, Y., and Anderson, J., 2000, Evaluation of numerical procedures for simulating near-fault long-period ground motions using Zeng method.

Zhou, H.-L., Allen, C.R., and Kanamori, H., 1983, Rupture complexity of the 1970 Tonghai and 1973 Luhuo earthquakes, China, from P-wave inversion, and relationship to surface faulting: Bull. Seism. Soc. Am., v. 73, no. 6, p. $1585-1597$.

Zhou, Y.H., Xu, L.S., and Chen, Y.T., 2002, Source process of the 4 June 2000 southern Sumatra, Indonesia, earthquake: Bull. Seism. Soc. Am., v. 92, no. 5, p. 2027-2035.

Zobin, V.M., and Pizano-Silva, J.A., 2007, Macroseismic study of the $\mathrm{M}_{\mathrm{w}} 7.521$ January 2003 Colima, México, across-trench earthquake: Bull. Seism. Soc. Am.,v. 97, no. 4, p. 1221-1232. 


\section{Appendix III - Complete List of Atlas}

\section{Events}

Comma delimitered ASCII file with complete list of 4,856 events compiled for Atlas research as of April 2008 (see Appendix_III.csv).Earthquake source information was taken from the preferred origin time, hypocentral location and magnitude of PAGER-CAT (see http://earthquake.usgs. gov/research/data/pager/). Fields included in the database are listed below:

\begin{tabular}{ll}
\hline \multicolumn{1}{c}{ PAGER-CAT FIELD } & \\
\hline EQID & Earthquake identification number (based origin time) \\
EQNAME & Name of earthquake \\
YYYY & Year of earthquake \\
MM & Month of earthquake \\
DD & Day of earthquake \\
HH & Hour of earthquake \\
MN & Minute of earthquake \\
SEC & Second of earthquake \\
LAT & PAGER preferred latitude \\
LON & PAGER preferred longitude \\
DEPTH & PAGER preferred depth \\
MAG & PAGER preferred magnitude \\
MAGTYPE & PAGER preferred magnitude type \\
COUNTRY & International Organization for Standardization country \\
COUNTRY_CODE & International Organization for Standardization two letter country code \\
ARCDIST & Location distance to nearest landmass (degrees; equals zero if within political borders) \\
PREFSHAKINGDEATHS & PAGER preferred shaking deaths \\
SHAKEMAP_UNCERT & Average uncertainty of ShakeMap \\
SHAKEMAP_GMPE & GMPE used for ShakeMap \\
& \\
\hline
\end{tabular}


Publishing support provided by:

Denver Publishing Service Center

For more information concerning this publication, contact:

Team Chief Scientist, USGS Geologic Hazards

Box 25046, Mail Stop 966

Denver, CO 80225

(303) 273-8579

Or visit the Geologic Hazards Team Web site at: http://geohazards.cr.usgs.gov/ 


$$
\frac{\mathbb{2}}{80}
$$

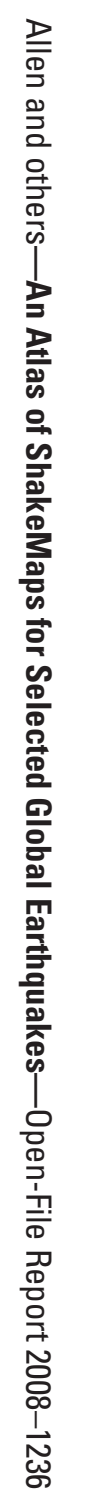

